
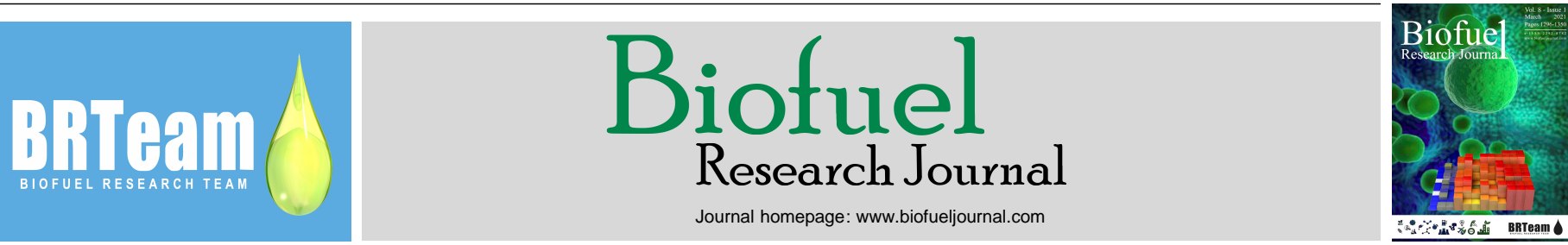

Review Paper

\title{
A review on the modeling and validation of biomass pyrolysis with a focus on product yield and composition
}

\author{
Changlei Xia ${ }^{1,2,}$, Liping Cai ${ }^{1,2,}$, Haifeng Zhang ${ }^{1}$, Lei Zuo ${ }^{3}$, Sheldon Q. Shi ${ }^{1, *}$, Su Shiung Lam ${ }^{4, *}$ \\ ${ }^{1}$ Department of Mechanical Engineering, University of North Texas, Denton, Texas 76203, USA. \\ ${ }^{2}$ Co-Innovation Center of Efficient Processing and Utilization of Forestry Resources, College of Materials Science and Engineering, Nanjing Forestry \\ University, Nanjing, Jiangsu 210037, China. \\ ${ }^{3}$ Mechanical Engineering, NSF I/UCRC Center for Energy Harvesting Materials and Systems (CEHMS), Virginia Tech, 311 Durham Hall, Blacksburg, VA \\ 24061, USA. \\ ${ }^{4}$ Higher Institution Centre of Excellence (HICoE), Institute of Tropical Aquaculture and Fisheries (AKUATROP), Universiti Malaysia Terengganu, 21030 \\ Kuala Nerus, Terengganu, Malaysia.
}

\section{HIGHLIGHTS}

$>$ Biomass pyrolysis methods and modeling are reviewed.

$>$ Pyrolysis mechanisms considering the effects of different biomass components are presented. $>$ Models used for predicting product yields along with validation methods are reviewed and discussed. $>$ Recommendations on using high-temp gas sensors to determine gas yield and composition are provided.

\section{GRAPHICAL ABSTRACT}

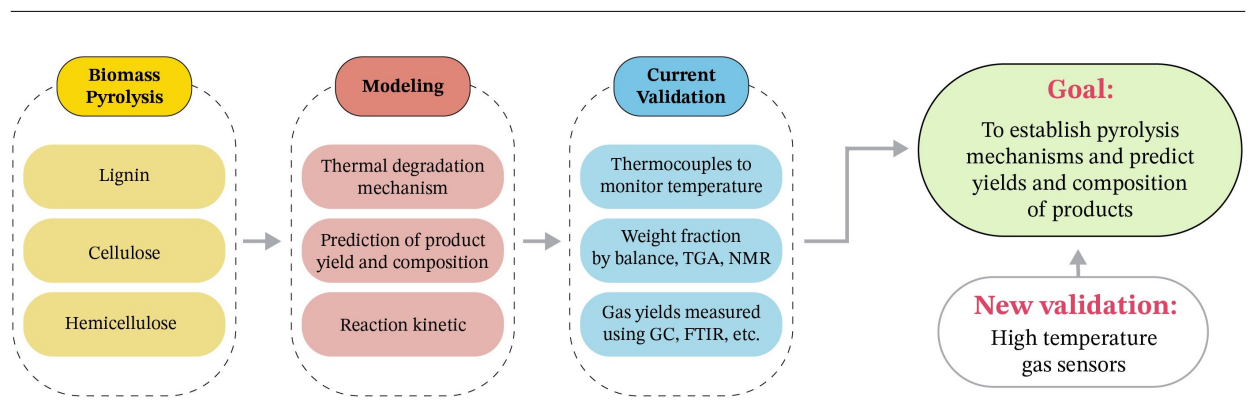

\section{ARTICLE INFO}

\section{Article history:}

Received 12 September 2020

Received in revised form 9 December 2020

Accepted 8 January 2021

Available online 1 March 2021

\section{Keywords:}

Bioenergy

Lignocellulose

Biomass

Pyrolysis

Reaction kinetics

Sensor

\begin{abstract}
Modeling is regarded as a suitable tool to improve biomass pyrolysis in terms of efficiency, product yield, and controllability However, it is crucial to develop advanced models to estimate products' yield and composition as functions of biomass type/characteristics and process conditions. Despite many developed models, most of them suffer from insufficient validation due to the complexity in determining the chemical compounds and their quantity. To this end, the present paper reviewed the modeling and verification of products derived from biomass pyrolysis. Besides, the possible solutions towards more accurate modeling of biomass pyrolysis were discussed. First of all, the paper commenced reviewing current models and validating methods of biomass pyrolysis. Afterward, the influences of biomass characteristics, particle size, and heat transfer on biomass pyrolysis, particle motion, reaction kinetics, product prediction, experimental validation, current gas sensors, and potential applications were reviewed and discussed comprehensively. There are some difficulties with using current pyrolysis gas chromatography and mass spectrometry (Py-GC/MS) for modeling and validation purposes due to its bulkiness, fragility, slow detection, and high cost. On account of this, the applications of Py-GC/MS in industries are limited, particularly for online product yield and composition measurements. In the final stage, a recommendation was provided to utilize high-temperature sensors with high potentials to precisely validate the models for product yield and composition (especially $\mathrm{CO}_{2} \mathrm{CO}_{2}, \mathrm{and}_{2}$ ) during biomass pyrolysis.
\end{abstract}

(c) 2021 BRTeam. All rights reserved.

* Corresponding authors at:

E-mail addresses: sheldon.shi@ unt.edu (Sheldon Q. Shi) ; lam@umt.edu.my (Su Shiung Lam)

7: These authors contributed equally.

Please cite this article as: Xia C., Cai L., Zhang H., Zuo L., Shi S.Q., Lam S.S. A review on the modeling and validation of biomass pyrolysis with a focus on product yield and composition. Biofuel Research Journal 29 (2021) 1296-1315. DOI: 10.18331/BRJ2021.8.1.2 


\section{Contents}

1. Introduction.

1.1. General reviews on biomass pyrolysis technologies

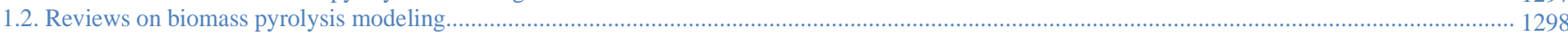

1.3. Reviews on upgrading of pyrolysis products

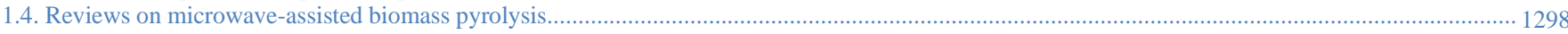

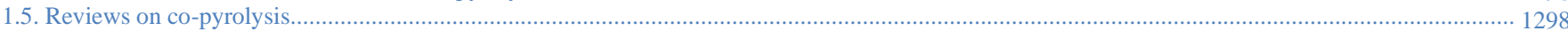

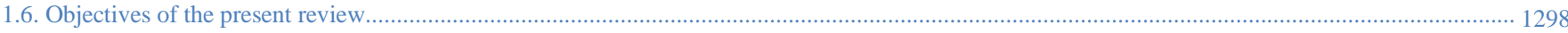

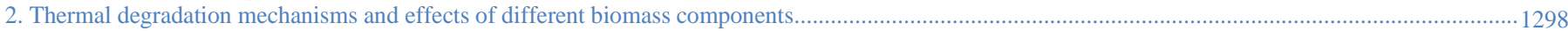

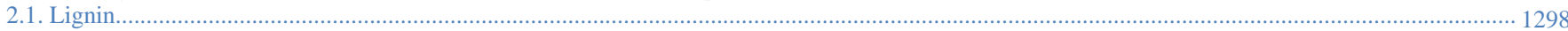

2.2. Cellulose

2.3. Hemicellulose

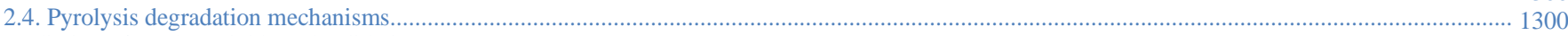

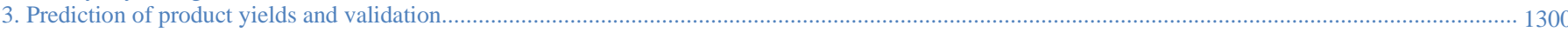

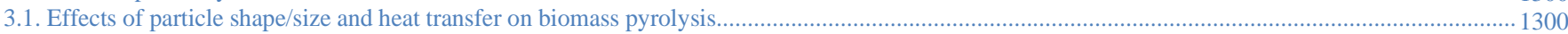

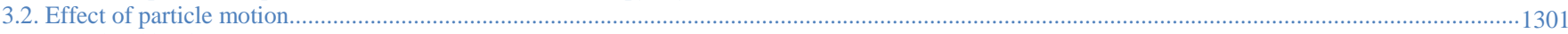

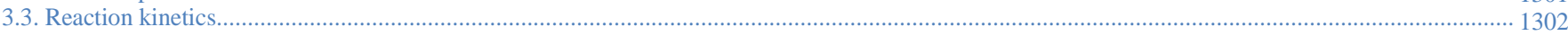

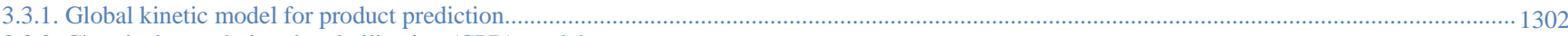

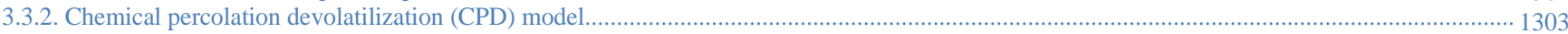

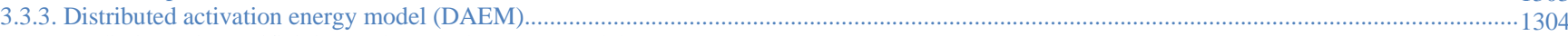

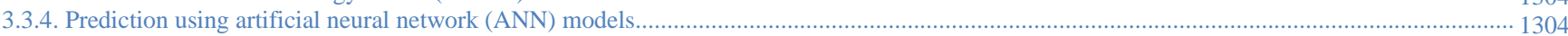

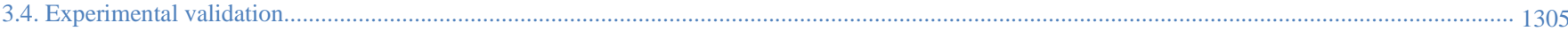

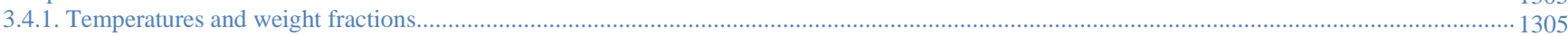

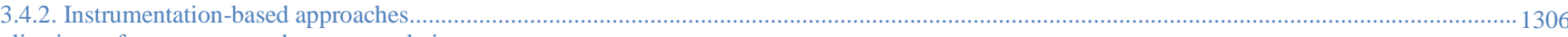

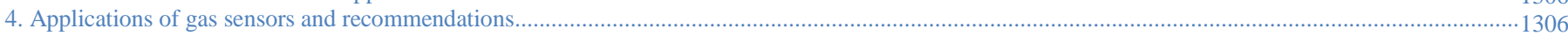

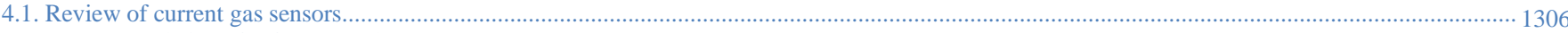

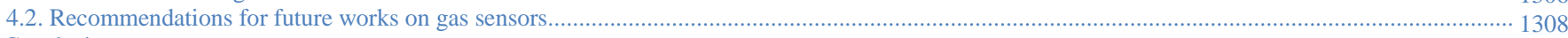

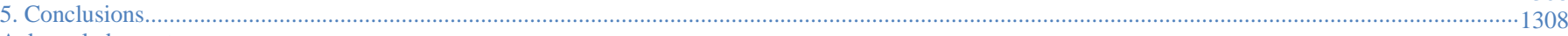

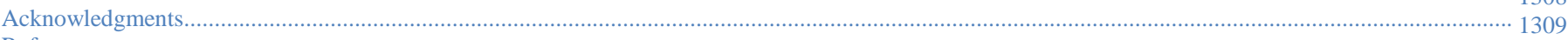

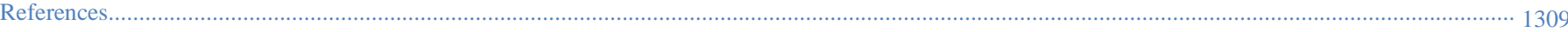

\section{Introduction}

Lignocellulosic materials are abundant and geographically-dispersed, comprising a complex mixture of three major components, i.e., cellulose, hemicellulose, and lignin (Soltanian et al., 2020). Due to their environmentally friendly properties, biomass-oriented products are considered an indispensable part of a sustainable society. In line with that, biomass-originated energy carriers have been widely endorsed as future energy sources to partially or entirely substitute their petroleum-based counterparts. Among the various techniques used to exploit biomass energy, pyrolysis has attracted a great deal of attention because of its high efficiency (Tripathi et al., 2016; Lam et al., 2019e; Ge et al., 2020b) in converting biomass into various products, including charcoal, condensable vapors (i.e., tar or bio-oil), and permanent gases (Lam et al., 2019d; Yek et al., 2019; Ge et al., 2020a). From the mechanistic viewpoint, biomass pyrolysis processes include sequential steps, i.e., biomass depolymerization, monomer conversion and vaporization, and vapor conversion into ultimate products. The details of the process's chemical mechanism can be described based on the molecular changes observed throughout the involved reactions. An accurate mechanistic description of biomass pyrolysis can identify the intermediate biomolecules involved in the process, which is regarded as a complicated procedure, requiring substantial research efforts (Yek et al., 2019).

During the biomass pyrolysis process, it is desired to produce high-quality pyrolysis products by optimizing process parameters, i.e., pyrolysis temperature and heating rate, biomass dwelling time inside the reactor, and feedstock type. For instance, applying a high heating rate can reduce unwanted charring reactions of biomass feedstock (Papadikis et al., 2009). As the reactor parameters are adjustable, various models have been developed to simulate biomass heat transfer and momentum balance mechanism and reaction during biomass pyrolysis. These models are introduced and discussed in this review paper. Besides, the previously published review articles on biomass pyrolysis technologies and modeling are also reviewed and summarized.

\subsection{General reviews on biomass pyrolysis technologies}

To date, a considerable number of review articles have been published on biomass pyrolysis. Radlein and Quignard (2013) reviewed the advances in biomass pyrolysis technologies focusing on thermal degradation for bio-oil production. They argued that using high temperatures and high heating rates played essential roles in boosting liquid yields. However, the low physicochemical properties of bio-oil hamper its functionality in pure applications. Due to biomass's low thermal conductivity, small particle sizes and uniform heating rates are suggested. With the aim of process scale-up, several innovative approaches have been presented to address the particle size limitation. The authors remarked that a wide range of particle sizes could be used in auger pyrolysis reactors. They also underlined the need for advanced technologies to be practical for different feedstocks types (Radlein and Quignard, 2013).

Collard and Blin (2014) reviewed the pyrolysis of individual lignocellulosic components, i.e., cellulose, hemicelluloses, and lignin. They pointed out that the mass superposition of product yields of individual components could determine the total product yields for both primary and secondary reactions. It has been shown that lignin is principally responsible for the highest char production and various phenols formation.

Tripathi et al. (2016) reviewed char production using bio-originated materials. They showed that the biochar yield was significantly dependent on the feedstock properties (i.e., biomass type, moisture content, and raw material size), reaction temperature and time, heating rate, carrier gas type, and biomass flow rate. In another study, Kan et al. (2016) reported that reaction temperature and heating rate were highly critical for the pyrolysis product quantities. More specifically, elevated heating rates produced higher liquid but lower biochar yields. The pyrolysis temperatures ranging from 400 to $550{ }^{\circ} \mathrm{C}$ were regarded as the optimum setpoints to maximize bio-oil and solid product yields. It has been reported that high-temperature catalytic pyrolysis favored forming permanent gases. As discussed earlier, this study also highlighted that a reduction in particle size could increase product yields due to the facile heat diffusion into the particle. It is important to note that thermal pretreatment could reduce particles' moisture and oxygen contents, resulting in improved energy efficiency and product quality. Chemical and biological pretreatments could augment bio-oil yield by mitigating biomass's mineral matter and lignin content (Kan et al., 2016). It should be taken into consideration that particle shrinkage rate and 
heating source are influential considerations for the pyrolysis modeling concept.

\subsection{Reviews on biomass pyrolysis modeling}

There are a handful of review articles focusing on the pyrolysis modeling of biomass. In this context, Sharma et al. (2015) reviewed the developments of mathematical modeling for particle movement and its interaction with the carrier gas flow during pyrolysis. They demonstrated that computational fluid dynamics (CFD) models could be practical tools to simulate the pyrolysis process in different pyrolysis temperatures, times, and feedstock composition and size. In their study, models were also developed to estimate biomass catalytic cracking and bio-oil catalytic upgrading for bioenergy. However, it should be noted that the current biomass pyrolysis models are still suffering from many imperfections and are not capable of accurately estimating product yields. In the two-step kinetics models, which include both primary and secondary reactions, the pyrolysis rate for different feedstock types could not often be precisely calculated since they do not consider particle shrinkage's effect on its degradation rate. Papari and Hawboldt (2015) reviewed the biomass pyrolysis mechanisms in large-scale reactors and compared the results with the experimental data obtained from a lab-scale tube reactor. They concluded that the most accurate model for predicting the pyrolysis product yields was the chemical percolation de-volatilization model developed by Lewis and Fletcher (2013). They showed that the competitive model introduced by Chan et al. (1985) was also in a good agreement with the experimental biooil yields. The utilization of the distributed activation energy model (DAEM) in the pyrolysis of biomass was reviewed by Cai et al. (2014).

\subsection{Reviews on upgrading of pyrolysis products}

Isahak et al. (2012) reviewed the physical, catalytic, and chemical modifications to upgrade bio-oil properties. Shen and Yoshikawa (2013) studied the advances in catalytic tar elimination for the biomass pyrolysis/gasification processes and explained the non-catalytic tar removal under room temperatures. They reported that tars could be eliminated in scrubbers by combining catalytic restructuring and oil adsorption. The former would play a more critical role in the biomass pyrolysis process. Bridgwater (2012) and Zhang et al. (2007) reviewed bio-oil production during pyrolysis and highlighted the research on modifying primary liquid properties. They implied that most studies investigating bio-oil production were rudimentary by considering only the main species' mixtures in bio-oil. In fact, the application of limited component mixtures would not reflect the complexity of bio-oil characteristics. The authors claimed that the integration of fast pyrolysis and bio-oil upgrading would be a future trend in advanced pyrolysis technologies.

To this end, Asadieraghi et al. (2015) recommended microporous zeolites, mesoporous catalysts, and metal-based catalysts to upgrade the vapor-phase bio-oil effectively. It has been shown that the bio-oil and char quality can be improved by adding metal chlorides during the catalytic pyrolysis of alkali lignin (Wang et al., 2015). Moreover, many studies reported that incorporating nickel salts could reduce tar yield and oxygen content of the bio-oil produced in lignin pyrolysis and increase hydrogen production and gas yield (Ma et al., 2014; Geng et al., 2017). Overall, the quality of bio-oil currently obtained from biomass pyrolysis is still a primary concern. Therefore, bio-oil upgrading is considered one of the most critical challenges to be tackled by future studies (Kong et al., 2019; Lam et al., 2019b and c).

\subsection{Reviews on microwave-assisted biomass pyrolysis}

According to the reviews on microwave-assisted pyrolysis (MAP) of biomass (Yin, 2012) and pyrolysis carbonization technologies (Si et al., 2015), it could be concluded that MAP would be one of the most promising biomass pyrolysis methods because the microwave dielectric heating could effectively heat biomass feedstocks at the heating stage. Predictably, the required equipment for biomass pyrolysis would be of simple and portable when using microwave heating. Macquarrie et al. (2012) and Morgan et al. (2017) reviewed the MAP of various biomass types under different conditions to produce char, bio-oil, and permanent gases (e.g., $\mathrm{CO}_{2}, \mathrm{CO}, \mathrm{CH}_{4}$, and $\mathrm{H}_{2}$ ). It was suggested that the future MAP research work should focus on catalyst selection, reaction optimization, and pyrolysis process simulation in order to attain high-grade biooil. The microwave absorbers and commonly used catalysts in MAP and the characteristics and yields of bio-chars were reported by Li et al. (2016). An overview of MAP technology by Zhang et al. (2017) explored the fundamental microwave irradiations, various kinds of catalysts, types of microwave absorbers, chemistry of non-catalytic MAP, and chemistry of catalytic MAP. Compared to conventional heating, MAP could produce higher quality products due to the key advantages of rapid and controllable heating, energy-saving process, and no need for agitation or fluidization in the reactors (Liew et al., 2018; Lam et al., 2019a).

\subsection{Reviews on co-pyrolysis}

Co-pyrolysis is referred to the simultaneous application of two different types of feedstocks in one pyrolysis process. Plenty of studies have demonstrated that co-pyrolysis can improve bio-oil yield and caloric value while reducing the products' moisture content (Abnisa and Daud, 2014; Mahari et al., 2018a and b). It is noteworthy that the co-feeding of plastics and rubbers with biomass (e.g., sawdust) could improve pyrolysis oil (Wang et al., 2014). Summaries of the review articles published on biomass pyrolysis methods and modeling are presented in Table 1.

\subsection{Objectives of the present review}

It is much desired to accurately predict product yields based on pyrolysis parameters and biomass properties due to the diversity of feedstocks. Several review articles have discussed pyrolysis modeling of biomass through thermochemical conversion processes while inclined towards microwave-assisted biomass pyrolysis and biomass co-pyrolysis. However, to the best of our knowledge, none of them has focused on predicting product yields and validation. In light of that and having summarized previous reviews published on various aspects of pyrolysis, the present review presents and discusses thermal degradation mechanisms and effects of different biomass components. Afterward, the influences of biomass characteristics, particle size, and heat transfer on biomass pyrolysis, particle motion, reaction kinetics, product prediction, experimental validation, current gas sensors, and potential applications are scrutinized comprehensively. Finally, gas sensors and their applications in pyrolysis reactors are explained, and future perspectives for pyrolysis research are provided.

\section{Thermal degradation mechanisms and effects of different biomass components}

As a natural polymer with a complex structure, lignocellulosic biomass comprises lignin [18-40 wt\% (Amen-Chen et al., 2001)], cellulose [40-90 wt\% (Goodwin et al., 1972)], and hemicellulose [20-35 wt\% (Di Blasi and Lanzetta, 1997; Spearpoint, 1999)], as well as trace amounts of extractives and ash. Thermal degradation is a complex process through which biomass particles simultaneously undergo many different reactions, such as dehydration, depolymerization, fragmentation, and carbonization, producing liquid oil, char residues, and gaseous products (Patwardhan et al., 2011).

\subsection{Lignin}

With a complex structure, lignin includes guaiacol, syringol, and phydroxylphenyl, bonded through ether bonds (McKendry, 2002; CalvoFlores and Dobado, 2010). Through thermal conversion, lignin could be a promising feedstock for producing different phenolic compounds and aromatic hydrocarbons, serving as biofuels and biochemicals (Jakab et al. 1995; Yaman, 2004). Numerous analytical modeling and experiments have been carried out to obtain a more in-depth understanding of lignin's pyrolysis mechanism and improve its conversion efficiency (Hu et al. 2013; Shen et al., 2010b).

Liu et al. (2008) explored the performance of two types of lignin, birch and fir, using the thermogravimetric Fourier transform infrared (TG-FTIR). It was found that the primary volatiles released were phenols at temperatures ranging from 150 to $287{ }^{\circ} \mathrm{C}$, while $\mathrm{CO}_{2}$ and $\mathrm{CH}_{4}$ were significantly released when the temperature was increased to $327-427^{\circ} \mathrm{C}$. Consistently, it was also reported that $\mathrm{CH}_{4}, \mathrm{CO}$, and phenols were the most important substances released at the mass-loss stage (Yang et al. 
Table 1.

A summary of the review articles on biomass pyrolysis methods and modeling.

Theme of the review Sub-theme

A short historical review of fast pyrolysis of biomass

Mechanisms/ composition of products from the conversion of biomass

General reviews on

biomass pyrolysis technologies

Effect of process parameters on production of biochar

Product properties and effects of pyrolysis parameter

Modeling, process parameters and catalytic studies

Reviews on biomass pyrolysis modeling

Reviews on upgrading of pyrolysis products

Upgrading bio-oil at its vapor phase

Adding nickel formate to alkali lignin to increase contents of alkylphenols and aromatics

Using biochar for methylene blue adsorption

\section{Microwave pyrolysis} carbonization technologies

MAP of various biomass types

Reviews on microwaveassisted biomass pyrolysis (MAP)

\section{Using absorbers and catalysts in} MAP

\section{Microwave absorbers and} catalytic MAP

Simultaneous application of two Reviews on co-pyrolysis

\section{Major findings or/and models}

- High temperatures and heating rates increased liquid yields.

- Small particle sizes were more favorable during pyrolysis

- Bio-oil yields were estimated by the mass superposition model, which can be used for primary and secondary reactions.

- Biochar yield was affected by feedstock properties, temperature/time, heating rate, carrier gas type, and flow rate.

- Higher heating rates produced higher quantities of liquid but lower bio-char yields.

- High yield and quality of syngas could be achieved by high-temperature catalytic pyrolysis.

- Particle movement and interaction in the carrie gas flow were modeled during pyrolysis. - CFD models were efficiently applicable to simulate pyrolysis processes.

- Used kinetic models to describe biomass pyrolysis mechanisms in large-scale reactors and compared the results with the results obtained using a labscale tube reactor.

- DAEM model was derived.

- Frequency and distribution of activation energy in DAEM and numerical simulation of parameter determination were presented.

- The principle of non-catalytic absorption for tar removal was explained.

- The orientation of research in using mixtures of major compounds to represent bio-oil production was implied.

- The vapor phase of bio-oil can be upgraded by the catalysts comprising microporous zeolites, mesoporous catalysts, and metal-based catalysts.

- During the pyrolysis of lignin, the addition of nickel salts can reduce tar yield and oxygen content of bio-oil.

- Self-purging microwave pyrolysis (SPMP) can convert oil palm shell into carbon-rich biochar

- The simplicity and portability of biomass pyrolysis equipment were highlighted when using microwave heating.

- Under various conditions, MAP could effectively produce chars, bio-oil, and gases (e.g., $\mathrm{CO}_{2}, \mathrm{CO}$, $\mathrm{CH}_{4}$, and $\mathrm{H}_{2}$ )

- The characteristics and yields of bio-chars from MAP were discussed

- MAP could produce higher quality products due to its key advantages of rapid and controllable heating.

- The co-pyrolysis could improve bio-oil yield and caloric value while reducing the moisture content of the products.

\section{Conclusions}

- A wide range of particle sizes could be accepted using auger pyrolysis

- The application of bio-oil is hampered by its low properties.

- Lignin fraction was primarily responsible for most of the char yield and various phenols.

Collard and Blin (2014)

- The pyrolysis parameters (e.g., temperature, time, and heating rate) were critical in affecting biochar yield.

- Optimum temperatures to maximize liquid and solid product yields were from 400 to $550^{\circ} \mathrm{C}$.

- The bio-oil yields could be increased by reducing lignin content through chemical pretreatments.

- The reviewed pyrolysis models suffered from many problems, mainly because their product

yields could not be accurately estimated.

Sharma et al. (2015)

- The most accurate model for predicting pyrolysis yields was the chemical percolation devolatilization model.

Papari and Hawboldt (2015)

- The DAEM model can be used in the biomass pyrolysis process.

Cai et al. (2014)

- Tars can be used as an alternative fuel to replace fossil fuels for heat and power generation.

Shen and Yoshikawa (2013)

- It remains unclear if the limited component mixtures could characterize the complexity of bio-

- Future studies on biomass pyrolysis should include the combination of fast pyrolysis and biooil upgrading.

- Bio-oil and char quality can be improved by adding metal chlorides during the catalytic pyrolysis of alkali lignin.

- Addition of nickel salts can reduce tar yield and increase gas yield.

- Upgrading of bio-oil could be the main challenge to be tackled by future studies because the bio-oil quality currently obtained from biomass pyrolysi is still insufficient.

- MAP is a promising biomass pyrolysis method because the microwave dielectric heating could effectively heat biomass at the heating stage.

- The future MAP research work should focus on catalyst selection and optimizing reaction conditions to improve product quality/yield.

- Addition of absorbers and catalysts improved quality and yields of bio-chars

- MAP process did not require agitation o fluidization in the reactors.

- Microwave absorbers helped to increase the heating rate.

- Quality and yield of bio-oil could be enhanced through co-pyrolysis.
Bridgwater (2012)

Zhang et al. (2007)

Asadieraghi et al

(2015); Wang et al.

(2015)

Geng et al. (2017)

Kong et al. (2019)

Yin (2012); Si et al. (2015)

Macquarrie et al.

(2012); Morgan et al.

(2017)

Li et al. (2016)

Zhang et al. (2017)

Abnisa and Daud,

(2014); Mahari et a (2018a and b) 
2007; Wang et al., 2009; Jiang et al., 2010; Hu et al., 2013). The different features of lignin between softwood (fir) and hardwood (maple) were compared by Zhao et al. (2014). They observed that lower amounts of methoxyl groups were contained in softwood lignin compared to hardwood lignin. Moreover, both lignins released aromatic compounds between 650 and $800{ }^{\circ} \mathrm{C}$ due to the scission of aryl-O-R linkages and the dehydroxylation reaction. Furthermore, the amounts of phenolic methanol and $\mathrm{CH}_{4}$ released during the pyrolysis of fir lignin were much smaller than those released from the maple lignin (Zhao et al., 2014).

\subsection{Cellulose}

Being the predominant part of biomass, exploring the cellulose pyrolysis mechanism has attracted a great deal of attention (McKendry, 2002; Sanders et al., 2003). Despite the deposition of hemicellulose and lignin, the cohesive interlaced cellulosic microfibrils construct the framework of biomass cell walls (Goodwin et al., 1972; Bauer et al., 1973). Cellulose is generally converted into liquid tar, gaseous products, and residual chars during the pyrolysis process through dehydrating, fragmentizing, and condensing reactions. The reaction temperature and heating rate are the most critical factors to determine the proportions of these products.

As a linear homopolysaccharide of b-D-glucopyranose units, cellulose thermal decomposition could be triggered by a low temperature of $150{ }^{\circ} \mathrm{C}$ (Shafizadeh, 1982). As soon as reaching $300{ }^{\circ} \mathrm{C}$, cellulose undergoes depolymerization reactions to yield bio-oil, consisting mainly of anhydrooligosaccharides and furans monomeric anhydrosugars (Pouwels et al., 1989; Patwardhan et al., 2009). Usually, higher quantities of gases could be obtained when higher reaction temperatures and heating rates are implemented. In contrast, higher char yields can be achieved when lower reaction temperatures and heating rates are applied (Luik et al., 2007; Uzun et al., 2007).

Several reaction pathways have been proposed to explain cellulose thermal decomposition (Shafizadeh and Fu, 1973; Shen and Gu, 2009). As a simple well-accepted pyrolysis mechanism, active cellulose is first formed through partial depolymerization and is then broken down into syngas and chars (Piskorz et al., 2000; Wooten et al., 2004; Shen et al., 2011; Collard and Blin, 2014). To expand this mechanism, Patwardhan et al. (2009) and Wang et al. (2012) investigated glucose as the representative of cellulose. In another study, a series of isotopically labeled d-glucose pyrolysis was conducted by Paine et al. (2008) to explore the details of glucose decomposition pathways. Patwardhan et al. (2009) studied glucose-based carbohydrates and showed that high temperatures could activate glycosidic linkages, producing intermediates to form levoglucosan. It is important to note that the intramolecular stabilization by the 1,6-glycosidic bond of anhydroglucopyranose (i.e., levoglucosan) is critically involved in the thermal degradation of cellulose (Ponder and Richards, 1991).

\subsection{Hemicellulose}

Being mostly composed of galactoglucomannans (glucomannans) and arabinoglucuronoxylan (xylan) (Dong et al., 2012), hemicellulose plays a vital role in the thermal decomposition of biomass (Werner et al., 2014). Generally, hemicellulose includes pentoses, hexoses, and hexuronic acids (Scheller and Ulvskov, 2010). With an amorphous structure, hemicelluloses are referred to as a range of polysaccharides, majorly xylan and mannan (Di Blasi and Lanzetta, 1997; Spearpoint, 1999). Due to xylan's commercial availability, it is extensively used as the representative substance to study the hemicellulose thermal decomposition (Bassilakis et al., 2001; Yang et al., 2007; Shen et al., 2010a). During the pyrolysis process, xylans undergo a weight loss at temperatures ranging from 190 to $350^{\circ} \mathrm{C}$, and their decomposition is associated with exothermal reactions (Yang et al., 2007; Shen et al., 2010a).

Werner et al. (2014) investigated the pyrolysis behavior of seven different hemicelluloses, i.e., $\beta$-glucan, arabinogalactan, arabinoxylan, galactomannan, glucomannan, xyloglucan, and xylan, applying three methods, i.e., thermogravimetric analysis (TGA) coupled with FTIR spectroscopy, differential scanning calorimetry (DSC), and pyrolysis gas chromatography and mass spectrometry (Py-GC/MS). They observed that xylan decomposition led to the production of high percentages of $\mathrm{CO}_{2}$ and low percentages of other components. The maximum mass loss rates occurred at temperatures ranging from 243 to $332{ }^{\circ} \mathrm{C}$, yielding fixed carbon ranging from $1.3 \%$ (for $\beta$-glucan) to $13.1 \%$ (for xylan) as well as syngas.

\subsection{Pyrolysis degradation mechanisms}

Biomass pyrolysis is a thermal conversion process achieved by robust chemical and physical interactions between biomass and its adjacent hightemperature conditions (Ranzi et al., 2008). It should be noted that the operation parameters and reactor types could remarkably affect char, tar or bio-oil, and syngas yields (Antal et al., 2003; Bridgwater, 2003). Although temperature is the most critical factor for product yields, many other parameters, such as heating rate, vapor residence time, and particle size, could also considerably influence product characteristics (Lu et al., 2009, Phanphanich and Mani, 2011; Apaydın-Varol and Pütün, 2012; Shoja et al. 2013). Accordingly, the pyrolysis conversion process can be classified into fast pyrolysis and conventional pyrolysis. The former involves high heating rates $\left(\sim 1000^{\circ} \mathrm{C} / \mathrm{min}\right)$, elevated temperatures $\left(400-600{ }^{\circ} \mathrm{C}\right)$, and short vapor residence time ( $<2 \mathrm{~s}$ ) with a quick cooling (Bridgwater and Peacocke, 2000). It should be noted that very high-temperature pyrolysis could favor producing higher non-condensable gases than tar and char (White et al., 2011). In contrast to fast pyrolysis, conventional pyrolysis employs lower temperatures and longer residence time (Dupont et al., 2007). It is necessary to model or predict the yields of gases and tar volatiles as a function of the process parameters to be able to estimate the desired products.

To describe the process reaction kinetics during pyrolysis, Pierucci and Ranzi (2008) developed a model at the production scale, which can be used for different reactor types. Accordingly, Ranzi et al. (2008) suggested that the mechanistic kinetic model should focus on four various aspects, including a) biomass characterization, b) biomass decomposition into syngas, tars, and solid residue (char), c) release of gas and tar species from secondary gas-phase reactions, and d) char gasification. In another study, Sun et al. (2016) proposed a four-step mechanism for the biomass pyrolysis process based on the findings reported previously by Lin and Huber (2009) and Van de Velden et al. (2010). The stages involved in this mechanism are a) biomass drying at temperatures below $100{ }^{\circ} \mathrm{C}$ to release moisture and some bound water, b) production of syngas (e.g., $\mathrm{CO}$ and $\mathrm{CO}_{2}$ ) and acetic acid at temperatures between 100 and $200{ }^{\circ} \mathrm{C}, \mathrm{c}$ ) conversion of most vapors into bio-oil and decomposition of particles with large molecules into char and gases at temperatures between 200 and $600{ }^{\circ} \mathrm{C}$, and d) secondary cracking at temperatures between 300 and $900{ }^{\circ} \mathrm{C}$ to convert volatiles into char and non-condensable gases.

\section{Prediction of product yields and validation}

It is challenging to accurately predict product yields of the biomass pyrolysis process due to the fact that it involves complicated physical and chemical conversions and produces a large number of various product species. A few decades ago, in a pioneering work, Suuberg et al. (1978) estimated product yields from brown coal pyrolysis in a fixed bed reactor. The effects of the heating rate, pyrolysis temperature, and residence time on the volatile products were explored. Later, Milosavljevic et al. (1996) investigated the thermodynamic aspects of cellulose pyrolysis and char formation. Their findings led to further improvements in the global kinetics of the biomass pyrolysis process.

\subsection{Effects of particle shape/size and heat transfer on biomass pyrolysis}

Since biomass particles are usually in irregular shapes and various sizes, they can affect the pyrolysis efficiency, phenomenological models have been developed to look into the mechanisms of biomass pyrolysis processes under different conditions (Papadikis et al., 2009). A longer time is needed for larger particles to transfer heat from the shell to the core and diffuse moisture from the core to the shell. Since the ratio of particle surface area to volume varies with the particle shape, it could considerably affect the rates of heating, drying, and devolatilization. For the sake of simplicity, three shape types, i.e., sphere, cylinder, and plate, are typically used for the modeling of biomass drying and pyrolysis (Fletcher et al., 2000). For instance, Lu and Hsieh (2010) explored the influence of different particle shapes (i.e., disc, cylindrical, and spherical) on drying, heating rate, and reaction rate. Using cylindrical biomass particles, Jalan and Srivastava (1999) investigated the effects of particle size and heating rate on the heat transfer and then the biomass decomposition rate. In a different study, Horbaj (1997) and Liliedahl and Sjöström (1998) also developed pyrolysis 
models by highlighting the role of the particle shape, e.g., prism, cylinder, or sphere.

The sphere is the most commonly used particle shape in modeling because it is the simplest one to be implemented in pyrolysis models. However, it has the lowest surface-area-to-volume ratio among all the shapes, so it appears inappropriate for modeling biomass particles (Liliedahl and Sjöström, 1998). Saastamoinen (2006) showed that spherical particles reacted more slowly than their counterparts of other shapes. In a fixed mass weight and reaction temperature, spherical particles were found to have the lowest volatility and highest tar yield compared to the particles of other shapes (Thunman et al., 2002). Under the assumption of one-dimensional heat and mass transfer, some simplified models were developed, into which the shape factor was brought as a variable (Thunman et al., 2002; Peters and Bruch, 2003; Saastamoinen, 2006).

Assuming the cylindrical nature of wood particles, Janse et al. (2000) implemented the conservation equations of mass, enthalpy, and momentum to achieve a successful simulation for the flash biomass pyrolysis process. In addition, Bliek et al. (1985) introduced the vapor flow model influenced by conversion time for the cylindrical particles at the particle surface temperature of over $800 \mathrm{~K}$. The results indicated that the reaction rate was the dominant factor affecting conversion time, while the particle shape and size did not show significant effects on conversion time. In contrast to this study, Lu and Hsieh (2010) reported that heat transfer dominated the pyrolysis process because particle shape/size substantially affected the conversion time.

Most computational fluid dynamics (CFD) models assume that biomass particles are spherical. Considering the multiphase flow, the mass balance equations in phase $i$ are as follows (Papadikis et al., 2009) (Eqs. 1-3):

$\frac{\partial\left(\varepsilon_{i} \rho_{i}\right)}{\partial t}+\nabla\left(\varepsilon_{i} \rho_{i} v_{i}\right)=m_{i}^{\prime}$

where $\varepsilon_{i}$ is the volume fraction, $\rho_{\mathrm{i}}$ stands for the density $\left(\mathrm{kg} / \mathrm{m}^{3}\right), v_{i}$ is the velocity vector $\left(u_{i}, v_{i}, w_{i}\right)(\mathrm{m} / \mathrm{s})$, and $m_{i}^{\prime}$ denotes the volumetric mass sources. Mass conservation shows that the sum of volumetric mass sources $\left(m_{i}^{\prime}\right)$ in all phases is equal to zero, formulated as below:

$\sum_{i=1}^{n} m_{i}^{\prime}=0$

The heat transfer is calculated by assuming that the diffusion takes place along the radius direction and by solving the following equation:

$\frac{\partial}{\partial t}\left(\rho C_{p} T\right)=\frac{1}{r^{2}} \frac{\partial}{\partial r}\left(k_{e f f} r^{2} \frac{\partial T}{\partial r}\right)$

where $C_{p}$ is the specific heat capacity $(\mathrm{J} / \mathrm{kgK}), r$ is the radius of the tube (m), and $k_{\text {eff }}$ denotes the effective thermal conductivity $(\mathrm{W} / \mathrm{mK})$.

\subsection{Effect of particle motion}

Numerous studies have focused on modeling different biomass pyrolysis reactors such as auger reactor, entrained flow, rotating cone, vacuum, fixed bed, fluidized bed, circulating fluidized bed, etc. (Mohan et al., 2006). Among these reactors, fluidized bed reactors were demonstrated to produce a stable product quality with a high thermal efficiency (Scott et al., 1999). However, biomass movement and reaction in a fluidized bed are complicated since both chemical and physical phenomena in the multiphase domain change with time and space (Liu et al., 2017). Typically, the flow regime in a fluidized-bed reactor is regarded as a two-phase turbulent flow in which solid and gas phase exchange heat and mass through mixed physical and chemical reactions (Pepiot et al., 2010). The CFD concept offers a mighty package to simulate the motion and decomposition of massive particles inside a fluidized bed during the biomass pyrolysis process. Although applying CFD models to a multiphase flow is cumbersome, its final results could provide important details about the reactor temperature distribution, particle moisture content, decomposition rate, and yields of products (Fan and Fox, 2008; van der Hoef et al., 2008). Given the computers' limited capabilities in the past, they could calculate the pyrolysis process in lab-scale reactors rather than in industrial-scale ones.
Basically, the CFD models of simulating particle dynamics in the multiphase flow are theoretically classified into the Eulerian and Lagrangian methods (Gerber et al., 2010). Both approaches can predict most of the fast pyrolysis parameters in a fluidized-bed reactor, such as the particles' flow, particle temperature and moisture, biomass conversion rate, and yields of products (Authier et al., 2009). Lathouwers and Bellan (2001) applied the Eulerian method in modeling the pyrolysis process in a fluidized-bed reactor by introducing the biomass decomposition kinetics into the CFD model. Gerber et al. (2010) utilized the Eulerian model to describe the pyrolysis process, in which the fluidized medium was char particles, and the experimental data then validated the predicted data. To increase the modeling accuracy, Xue et al. (2011 and 2012) suggested a CFD model considering the particle density variation caused by devolatilization. Ranzi et al. (2008) proposed an extensive kinetic mode for biomass pyrolysis, including estimation of gas and liquid yields, which was later used by Mellin et al. (2013 and 2014) to develop a new CFD model for the simulation of a fluidized-bed reactor.

In addition to the Eulerian method, the Lagrangian approach was also used to describe the particle motion by Newton's law, estimating particle decomposition rate without considering the particle crash (Fletcher et al. 2000). Using the Eulerian-Eulerian-Lagrangian CFD framework, Papadikis et al. (2008, 2009 and 2010) studied the biomass flow, internal particle heat and mass transfer, external particle interactions with the medium in a reactor, and particle shrinkage and reactions in order to simulate a single biomass particle in a pre-fluidized bed. In another study, Bruchmüller et al (2012) applied the Lagrangian method to model the movement of a vast number of wood particles ( $\sim 0.8$ million) in a fluidized-bed reactor and validated the simulation with experimental results.

As a notable study in the Lagrangian context, Di Blasi et al. (1993 and 1996) proposed a three-parameter shrinkage model in which the particle shrinkage was considered as a variable for a single biomass particle at a limited temperature condition. It should be noted that biomass motion is influenced by the drag force, gas flow, biomass residence time, as well as particle size and density that are changeable during the pyrolysis (Huang et al., 2014). These changes could also affect the secondary reaction rate and the results obtained (Wang et al., 2014). To simulate the particle decomposition in a fluidized bed, an innovative method, called quadrature method of moments, was proposed and coupled with the multiphase Eulerian CFD model by Fan and Fox (2008), Fan et al. (2004 and 2007), Marchisio and Fox (2005), and Passalacqua et al. (2010). This method was also applied to predict biomass particle sizes and distribution in a fluidizedbed reactor by Xue and Fox (2014).

To explain the changes in biomass particle size in fluidized reactors, Liu et al. (2017) developed a multiphase CFD framework using the Eulerian method by integrating the Di Blasi particle shrinkage model (Di Blasi, 1996). After considering the changes of particle size and density during pyrolysis, using pseudo-components, the global kinetic model with multistage was proposed to explore the shrinkage effects on solid, liquid, and gas yields. The change of the average particle diameter during the pyrolysis was determined by solving the particle population equation using the quadrature method of moments. The multiphase CFD model was also combined with the distributed activation energy model to study biomass decomposition by considering the impacts of the influential variables, such as the multiphase flow dynamics, pyrolysis temperature, heating rate, particle residence time, and reaction kinetics, on the yields of various products (Xiong et al., 2016).

As a brief theoretical explanation for the Lagrangian method, the force balance on the biomass particle moving with the carrier gas during the pyrolysis process leads to the equation of motion for the particles (Eq. 4) (Papadikis et al., 2009).

$\frac{d u_{p}}{d t}=F_{D}\left(u-u_{p}\right)+\frac{g_{x}\left(\rho_{p}-\rho\right)}{\rho_{p}}$

where $u$ is the carrier gas velocity $(\mathrm{m} / \mathrm{s}), u_{p}$ is the particle velocity $(\mathrm{m} / \mathrm{s}), g_{x}$ stands for the gravitational acceleration $\left(\mathrm{m} / \mathrm{s}^{2}\right), \rho$ denotes the gas density $\left(\mathrm{kg} / \mathrm{m}^{3}\right), \rho_{p}$ is the density of particle $\left(\mathrm{kg} / \mathrm{m}^{3}\right)$, and $F_{D}$ is the drag force which can be calculated by using Equation 5 .

$F_{D}=\frac{18 \mu}{\rho_{p} d_{p}^{2}} \frac{C_{D} R_{e}}{24}$ 
where $d_{p}$ is the diameter of the particle (m), $R_{e}$ is the Reynolds number, and $C_{D}$ is the drag coefficient proposed by Morsi and Alexander (1972) and Haider and Levenspiel (1989). The relative Reynolds number can be computed using Equation 6.

$R e=\frac{\rho d\left|u_{p}-u\right|}{\mu}$

where, $\mu$ is the viscosity $(\mathrm{kg} / \mathrm{ms})$.

\subsection{Reaction kinetics}

\subsubsection{Global kinetic model for product prediction}

To fully understand the biomass conversion process and accurately predict product yields during biomass pyrolysis, it is desired to develop wellestablished models. The design of a good biomass reaction scheme is essential to exactly describe the chemical changes and predict the product yields (Xiong et al., 2014). As a relatively simple scheme, a one-step global model describes one global reaction for the biomass pyrolysis processes. However, this scheme brings about several drawbacks, including a) incapability to describe the total mass loss as a function of pyrolysis temperature/resident time and b) incapability to accurately estimate the individual product yields and distributions (Di Blasi, 1998).

In order to address the negative points of the one-step approach, the twostep scheme is introduced, which considers primary and secondary reactions during the pyrolysis process. In the primary stage, biomass is thermally decomposed to produce chars, tars/bio-oil, and light gases. In the secondary stage, the intermediate tars and char resulting from the primary reactions undergo further cracking to yield syngas and activated carbon (Xia et al., 2016; Xia and Shi, 2016; Shi and Xia, 2017). A typical semi-global two-stage scheme is presented in Figure 1 (Papadikis et al., 2009).
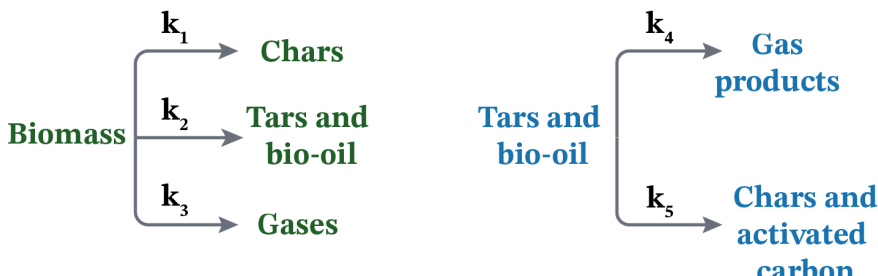

Fig. 1. Semi-global two-stage scheme for the biomass pyrolysis processes.

In this scheme, biomass usually degrades into three lump products, i.e., solid products (carbon and chars), liquid products (tars, water, and hydrocarbons), and gas products $\left(\mathrm{CO}_{2}, \mathrm{H}_{2} \mathrm{O}, \mathrm{CO}\right.$, and $\left.\mathrm{C}_{2-6} \mathrm{H}_{\mathrm{x}}\right)$ (Biagini et al., 2008; Ren et al., 2013). It should be noted that the heat/mass transfer and chemical kinetics are decisive factors in biomass molecular reactions during the pyrolysis process. These reactions could be classified into 1) biomass moisture losses at temperatures below $100{ }^{\circ} \mathrm{C}, 2$ ) primary phase pyrolysis at $200-600{ }^{\circ} \mathrm{C}$, in which biomass decomposes into the solid, liquid, and non-condensable gas products, and 3) secondary phase pyrolysis at $300-800^{\circ} \mathrm{C}$, in which vapors are condensed into tars or bio-oil, while large molecules are cracked to produce chars (Miller and Bellan, 1996).

Over recent years, a great deal of attention has been drawn toward maximizing gas production during biomass pyrolysis (Ferdous et al., 2001). With an increase in reactor temperature, the gas yields would be increased while the yields of bio-oils and char would be decreased (Bitowft et al., 1989; Demirbas, 2002; Li et al., 2004). Moreover, the increased reactor temperature could result in the high yields of $\mathrm{CO}$ and $\mathrm{H}_{2}$ and the low yields of $\mathrm{CH}_{4}$ and $\mathrm{CO}_{2}$ (Corella et al., 1988; Zanzi et al., 2002). Another factor affecting gas yield is the heating rate. At temperatures lower than $500{ }^{\circ} \mathrm{C}$, the gas and char yields decrease, whereas the bio-oil yield increases with an increase in heating rate.
Beyond the temperature of $500{ }^{\circ} \mathrm{C}$, the yields of char and liquid decrease while the yield of gases would increase (Zanzi et al., 1996; Li et al., 2004).

The global three-component kinetic model is frequently used to estimate the amount of gas products during biomass pyrolysis (Li et al., 2004). A method predicting the pyrolysis rates of biomass materials from the species compositions in terms of the primary constituents (cellulose, hemicellulose, and lignin) and their individual kinetic parameters, was proposed by Rao and Sharma (1998). In an experimental study using TGA, the effects of the different biomass components (hemicellulose, cellulose, and lignin) on the pyrolysis process were examined by Yang et al. (2006a). They observed that the interaction between the three components was negligible when the temperature and heating rate reached $900{ }^{\circ} \mathrm{C}$ and $10^{\circ} \mathrm{C} / \mathrm{min}$, respectively. The authors analyzed the relationship between component proportions and the biomass's weight loss during pyrolysis using multiple linear regression equations. Biagini et al. (2006) used the weighted summative law to calculate the TGA results and estimated the chemical composition of the obtained bio-oil. They subsequently validated the estimated results by the FTIR curves of the released volatile species.

Dupont et al. (2009) developed a model for high temperature (800-1000 $\left.{ }^{\circ} \mathrm{C}\right)$ and high heating fluxes $\left(10-100 \mathrm{~kW} / \mathrm{m}^{2}\right)$ to explore the general biomass pyrolysis performance using a kinetic pattern, including gas-phase reactions of the released species, which could predict the composition of main gases. Lu et al. (2011) carried out analytical Py-GC/MS to examine the pyrolysis vapors online during the fast pyrolysis of cellulose. Miller and Bellan (1996) developed a model by coupling the pyrolysis fluid flows with kinetics schemes for cellulose and wood. The comparisons of modeled results and experimental data indicated that the model associated with wood pyrolysis was not accurate, particularly at high temperatures. In this model, the modeled pyrolysis rates and tar yield were often higher than the experimental values. In a later work by the same researchers (Miller and Bellan, 1997), the biomass pyrolysis processes were modeled with multistep kinetics considering both primary biomass reactions and secondary tar decomposition reactions using a superposition principle of cellulose, hemicellulose, and lignin kinetics. This model could be used for typical biomass materials similar to the previous works done by Bradbury et al (1979) and Di Blasi and Russo (1993).

The literature focusing on predicting gas yields in the biomass pyrolysis is divided into two different groups. Some studies argue that it would be possible to estimate gas yields from the initial biomass composition. In contrast, others claim that that would be impossible due to the interactions among the different components and the effect of the mineral substances in biomass. For instance, Caballero et al. (1996) compared the yields of CO, $\mathrm{CO}_{2}$, and light hydrocarbons. They discovered that the predicted results using the global thermal decomposition model were not well-consistent with those obtained by the superposition of the decomposition kinetics for different components of almond shells.

In contrast to the mentioned studies, Couhert et al. (2009a and b) claimed that superposition law could not be a useful idea to predict pyrolysis gas yields due to the interaction among biomass components and the effect of minerals on pyrolysis reactions. There are several studies on the influence of mineral substances on prediction accuracy. Usually, the pre-washing method of biomass could eliminate the impact of minerals on pyrolysis reactions (Couhert et al., 2009a). Washing is generally performed with water or acid solutions. Di Blasi et al. (2000) investigated the effects of the minerals' extraction from biomass. It is important to note that the biomass composition of cellulose, hemicellulose, lignin, and extractives could be altered during the washing process (Das et al., 2004). In reality, not only minerals but also other components (e.g., extractives, hemicellulose) were removed during the washing treatment (Yang et al., 2006b).

Although there have been numerous types of equations for describing the kinetic analysis of biomass pyrolysis (Anca-Couce and Zobel, 2012 Trendewicz et al., 2014; Xiong and Kong, 2014; Papari and Hawboldt, 2015), the general fundamental equations for pyrolysis kinetics developed by Dizaji et al. (2014) are presented herein. Using the first-order Arrhenius law (Tran and Rai, 1978; Rath and Staudinger, 2001), it is assumed that the process of pyrolysis is a multi-step procedure and that each stage is governed by the Arrhenius law (Dizaji et al., 2014). The chemical pyrolysis kinetics for each step can be expressed as follows (Eq. 7): 
$\frac{d m}{d t}=-k\left(m-m_{f}\right)^{n}$

where $k=A \exp \left(-\frac{E}{R T}\right), n$ is the reaction order, $\mathrm{m}$ is the current mass, $m_{f}$ is the particle's final mass, $A$ denotes the pre-exponential coefficient, $E$ stands for the activation energy, and $R$ is the global gas constant. When the particle mass reaches $m_{f}$, the reaction stops $(d m / d t=0)$. Using the parameter of timedependent dimensionless mass decomposition $\left(\alpha=\left[m_{0}-m\right] /\left[m_{0}-m_{f}\right]\right.$, where $m_{0}$ is the initial mass), Equation 7 can be re-written to the following expression (Eq. 8):

$\frac{d \alpha}{d t}=k(1-\alpha)^{n}$

Substituting the Arrhenius kinetic equation for $k$ and using differentiation rules, $\alpha$-parameter can be expressed as follows (Eq. 9):

$\frac{d \alpha}{d T}=\frac{A}{H} \exp \left(-\frac{E}{R T}\right)(1-\alpha)^{n}$

where $H$ is the heating rate. By integrating Equation 9 and re-arranging it, the following expression can be obtained (Eq. 10).

$g(\alpha)=\frac{A E}{H R} p(x)$

where $x=E / R T$. The exponential integral $p(x)$ has no analytical solutions, but many approximate solutions can be found (Doyle, 1965; Flynn, 1997). With model-fitting methods, it is possible to find a suitable model to describe the influence of the relative changes in the particle mass $(\alpha)$ on temperature and simultaneously determine $E$ and $A$. One popular method is the Coats and Redfern method (Coats and Redfern, 1964; Vyazovkin and Wight, 1999), which is used herein.

By utilizing the exponential integration for both sides of Equation 10, the following equation can be obtained (Eq. 11):

$\ln \frac{g(\alpha)}{T^{2}}=\ln \left[\frac{A R}{H E}\left(1-\frac{2 R T}{E}\right)\right]-\frac{E}{R T}$

Eq. 11
By taking antilogarithm for both sides of Equation 11, the following expression is formed (Eq. 12):

$\frac{g(\alpha)}{T^{2}}=\exp \left(\ln \frac{A R}{H E}-\frac{E}{R T}\right)=\frac{\exp \left(\ln \frac{A R}{H E}\right)}{\exp \frac{E}{R T}}=\frac{\frac{A R}{H E}}{\exp \frac{E}{R T}}$

Eq. 12

Finally, the mean pyrolysis rate is calculated by using the pyrolysis kinetic constants (Eq. 13):

$\left(\frac{d m}{d t}\right)=\frac{\left\{-\int_{t_{1}}^{t_{2}}\left[\operatorname{Aexp}\left(-\frac{E}{R T}\right)\left(m-m_{f}\right)\right] d t\right\}}{\Delta t}$

Eq. 13

A typical algorithm for biomass pyrolysis modeling and validation is presented in Figure 2.

\subsubsection{Chemical percolation devolatilization $(C P D)$ model}

The CPD model was initially developed for describing changes in the chemical structure and devolatilization behavior of the coal during the rapid heating process (Fletcher et al., 1992). This model can predict char, tar, and light gas yields according to the heating rate, temperature, residence time, and pressure during the pyrolysis. The CPD model was extended from coal to biomass pyrolysis by Sheng and Azevedo (2002). The proposed model could estimate the pyrolysis behaviors of cellulose, hemicellulose, and lignin cnsidering their specific chemical structure (Sheng and Azevedo, 2002). With the same reaction scheme and multi-mechanisms in the coal model, the structural parameters were modified, and reaction kinetics were performed by considering the three components' reactions.

For the biomass pyrolysis process, an upgraded version of a network devolatilization model (bio-CPD) was introduced by Vizzini et al. (2008). Using the bio-CPD model, the authors could predict the yields of tar and major gas species, tars and chars, and the molecular weight distribution of tar in response to biomass's proximate and ultimate components, heating rate, temperature, and pressure in the reactor. Providing the initial organic chemical structure of black liquor or biomass, the CPD model was also
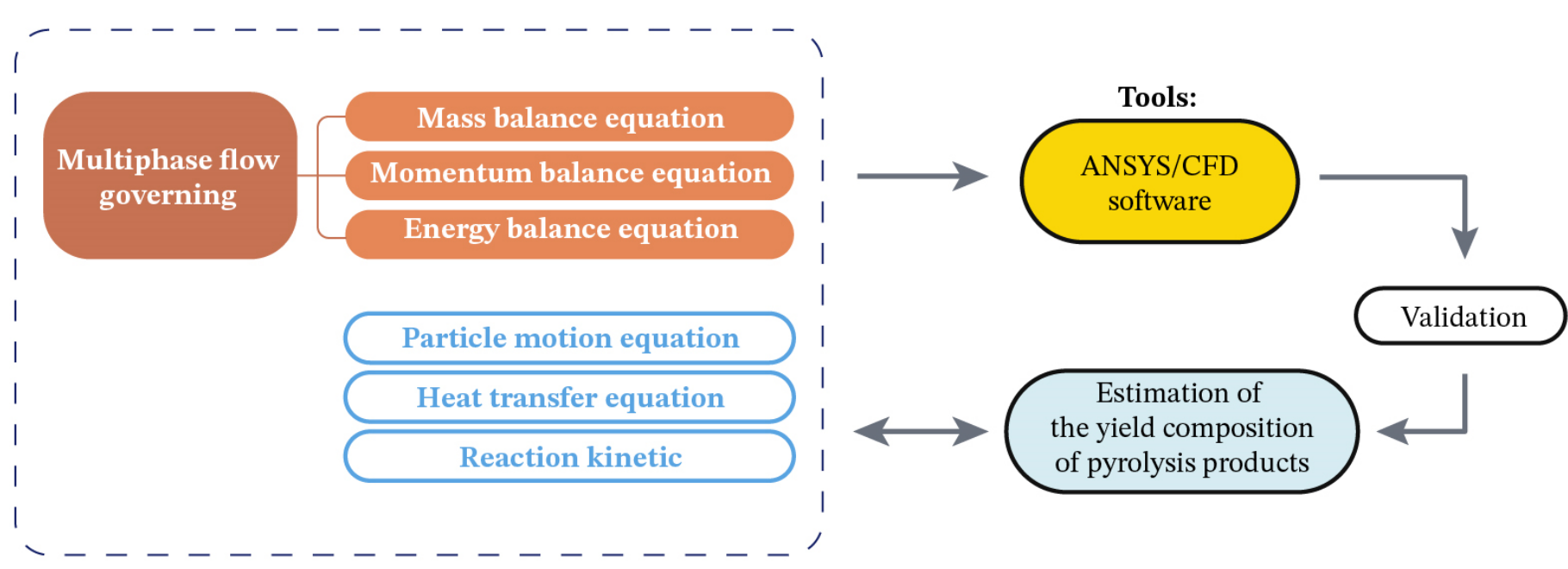

Fig. 2. Flowchart of biomass pyrolysis modeling and validation. 
extended to predict gas and tar yields using the ${ }^{13} \mathrm{C}$ NMR spectroscopy (Fletcher et al., 2012). Lewis and Fletcher (2013) modeled the sawdust pyrolysis process using the CPD model. The experimental results validated that the model could accurately estimate the devolatilization yields of three types of sawdust. Wan et al. (2015) also investigated the pyrolysis performances of coal, straw, and coal-straw blends using a one-dimensional, time-dependent bio-CPD model.

\subsubsection{Distributed activation energy model (DAEM)}

DAEM has been primarily employed to analyze complex reactions of fossil fuels, kerogen, carbon, and biomass, during pyrolysis (Mani et al., 2008; Chi et al., 2016). This model allows having different rate parameters co-occurring by assuming many irreversible first-order parallel reactions. Miura and Maki (1998) used the DAEM (Eq.14) to analyze total volatiles' change against time in the coal or biomass pyrolysis.

$1-\frac{V}{V^{*}}=\int_{0}^{\infty} \exp \left(-k_{0} \int_{0}^{T} e^{-\frac{E}{R T}} d t\right) f(E) d E$

Eq. 14

where $V$ is the emitted quantity of a volatile component at point $t, V^{*}$ is the total volatile quantity calculated from the activation energy at a small change interval during the pyrolysis reaction of samples, $V / V^{*}$ is the conversion rate of pyrolysis products at time point $t, k_{0}$ is the frequency coefficient, $E$ is the apparent activation energy, and $R$ is the ideal gas constant $\left(\sim 8.314 \mathrm{~J} \cdot \mathrm{mol}^{-1} \cdot \mathrm{K}^{-}\right.$ ${ }^{1}$ ). According to the Miura integration method (Miura and Maki, 1998), Equation 4 can be simplified as follows (Eq. 15):

$\ln \frac{\beta}{T^{2}}=\ln \frac{k_{0} R}{E}-\ln \left[-\ln \left(1-\frac{V}{V^{*}}\right)\right]-\frac{E}{R} \frac{1}{T}$

where $\beta=d T / d t$ represents the heating rate.

Using the Arrhenius equation, a further simplification of Equation 15 could be obtained as shown in Equation 16 (Chi et al., 2016):

$\ln \frac{\beta}{T^{2}}=\ln \frac{k_{0} R}{E}+0.6075-\frac{E}{R} \frac{1}{T}$

In the pyrolysis kinetic analysis, $E$ and $k_{0}$ are essential parameters describing the pyrolysis kinetic models, such as universal first-order (Coats and Redfern, 1964), comparison of linear heating rates (Friedman, 1964), section first-order (Lin et al., 2013), iso-conversion methods (Starink, 2003), distributed activation energy (Wang et al., 2009).

Rostami et al. (2004) developed a computer program to solve the models that incorporated DAEM into the CFD model to estimate yields of the individual pyrolysis materials at any heating rate and temperature conditions with the kinetic parameters were pre-determined by the TG-FTIR or TG-MS examination. Mani et al. (2008) utilized the DAEM equation to accurately predict the pyrolysis operation by the experimental data with several heating rates. Considering the temperature dependency of the pre-exponential coefficient in DAEM, the kinetic parameters for the non-isothermal lignin pyrolysis were determined using the annealing and TGA data.

The DAEM has recently been extensively applied to elaborate biomass pyrolysis under linear heating conditions (Sonobe and Worasuwannarak, 2008; Meng et al., 2013). Cai et al. (2013) extended the DAEM to a three-parallelreaction simulation for hemicellulose, cellulose, and lignin. They fitted the results to predict pyrolysis kinetic behaviors of eight types of biomass feedstocks. A review paper by the same group (Cai et al., 2014) discussed the DAEM methodology in terms of numerical calculation, parameter estimation methods, and applications in biomass pyrolysis. Combining the DAEM approaches detailed in this review with a multi-fluid CFD model (Xue et al., 2012), Xiong et al. (2016) simulated different phases of the biomass process. They showed that the activation energy distribution functions of Gaussian and Logistic could be more accurate in simulating pyrolysis kinetics. Hu et al. (2016) investigated the slow pyrolysis of three typical biomass feedstocks, i.e., bamboo, wood, and rice husk, using the combined DAEM method and model-free/Fraser-Suzuki deconvolution method, providing another alternative for kinetic analysis of slow biomass pyrolysis.

\subsubsection{Prediction using artificial neural network (ANN) models}

Over the recent years, some concerns have arisen about the accuracy of the models using the exclusive effects of individual biomass components (Peters, 2011; Burhenne et al., 2013; Garcia-Maraver et al., 2013). These models could not precisely predict product yields of biomass pyrolysis since the complex interactions between biomass compounds were ignored (Couhert et al., 2009b). The ANN concept is becoming more popular to solve complex nonlinear and discrete systems and to cover a large diversity of applications (Leonard and Kramer, 1990). For instance, ANN methodology has been successfully applied for modeling and optimization of biosorption processes due to the fact that it is capable of quantifying the interactions between different variables (Witek-Krowiak et al., 2014).

Moreover, ANN has also been used for biomass gasification to predict the syngas composition for different gasifier types (Guo et al., 2001; Brown et al., 2007; de Souza Jr et al., 2012; Puig-Arnavat et al., 2013; Mikulandrić et al., 2014; Kumar et al., 2016; Baruah et al., 2017). Using the generalized feedstock-independent ANN model, Guo et al. (2001) reported that the prediction accuracy was improved compared to the traditional feedstockdependent model. Utilizing the data from the published literature for the ANN model training, the syngas yield and the composition of the four major gases (i.e., $\mathrm{CO}, \mathrm{CO}_{2}, \mathrm{H}_{2}, \mathrm{CH}_{4}$ ) were estimated (Puig-Arnavat et al. 2013). This model used the back-propagation algorithm; the input layer included the biomass composition and several operation parameters, and the hidden layer had two neurons. The results estimated by the ANN model indicated a remarkable consistency with the experimental data.

In an interesting study, Mikulandrić et al. (2014) compared the equilibrium model and ANN model in the biomass gasification process, revealing that both approaches could reasonably predict the process parameters. Brown et al. (2007) estimated the gasifier's zone temperatures by integrating the ANN regressions with the stoichiometric equilibrium model. In this technique, the equilibrium model was modified by the outputs obtained from the ANN estimation. Applying an ANN model, Kumar et al. (2016) prognosticated the calorific values and syngas compositions for both air and steam gasification for different input parameters, including air flow rate, fuel flow rate, steam flow rate, fuel composition, and reaction temperature, which exhibited a good prediction accuracy.

In addition to biomass gasification applications, Sun et al. (2016) applied a three-layer ANN model for pine sawdust's pyrolysis to investigate the effects of the pyrolysis temperature, biomass size, and carrier gas flow velocity on the yields of major gaseous products $\left(\mathrm{H}_{2}, \mathrm{CO}, \mathrm{CH}_{4}\right.$, and $\left.\mathrm{CO}_{2}\right)$. In another work, Cepelioğullar et al. (2016) used the heating rate and pyrolysis temperature as inputs and the biomass weight loss as output to predict the thermal decomposition of two fuel types, indicating the usefulness of the ANN strategy in biomass pyrolysis. In line with this evidence, Baruah et al. (2017) closely validated the predicted results for the major gas species compositions at different operating parameters by the experimental data

Sunphorka et al. (2015) proposed an ANN model to quickly predict the kinetic parameters using the 100-point TGA data during the biomass oxidation process. In their study, the oxygen concentration, air-to-biomass ratio, carbon percentage, volatile substance percentage, and ash percentage were regarded as input data, and the pre-exponential coefficient, activation energy, and reaction order were considered as the outputs. In another research work by Sunphorka et al. (2017), three ANN models for the kinetic parameters were developed to estimate their correlations with biomass constituents. A set of 150 TGA data from different biomass compositions was used to train and test the models. The authors proved that the developed ANN models could estimate pyrolysis kinetic parameters with an acceptable accuracy.

Aghbashlo et al. (2019) expanded the data bank compiled by Sunphorka et al. (2017) by 42 additional points to develop three hybrid ANN-based models to forecast the kinetic parameters of biomass thermal conversion. Comparing the results by Sunphorka et al. (2017), they showed that the adaptive network-based fuzzy inference system (ANFIS) tuned with 
particle swarm optimization algorithm could significantly improve the prediction accuracy for biomass pyrolysis. In a later investigation, Aghbashlo et al. (2021) consolidated the ANFIS algorithm with the genetic algorithm to develop a hybrid intelligent model to study biomass thermal decomposition. They evidenced that evolutionary algorithms could remarkably strengthen the ANN models.

\subsection{Experimental validation}

Different validation methods for the prediction of pyrolysis products in literature are summarized in Table 2.

\subsubsection{Temperatures and weight fractions}

Since the radiation adsorption can occur in the vicinity of thermocouples in reactors, it is difficult to precisely determine the particle surface temperature. Authier et al. (2009) used an image furnace to address this problem and measured the particle surface temperatures during biomass pyrolysis. Gerber et al. (2010) monitored the temperature changes by inserting thermocouples inside the reactor. Corbetta et al. (2014) developed an experimental device for the large wood particle pyrolysis by inserting thin thermocouples into the particles. With a different approach, Suuberg et al. (1996) estimated the temperatures during pyrolysis by measuring the tar

Table 2.

Different models and validation methods.

\begin{tabular}{|c|c|c|c|c|c|}
\hline Authors & Reactor type & Model & $\begin{array}{l}\text { Temperature and } \\
\text { particle size }\end{array}$ & Validation remark(s) & Conclusions \\
\hline Oja and Suuberg (1999) & TGA apparatus & Clausius-Lapeyron equation & • $344-488 \mathrm{~K}$ & $\begin{array}{l}\text { The vapor pressures of R-D-glucose, } \\
\text { D-xylose, D-cellobiose, and } \\
\text { levoglucosan were measured. }\end{array}$ & $\begin{array}{l}\text { Knudsen effusion was a reliable } \\
\text { method. }\end{array}$ \\
\hline $\begin{array}{l}\text { Bandyopadhyay et al. } \\
\text { (1996) }\end{array}$ & Vertical fixed-bed reactor & $\begin{array}{l}\text { Heat } / \text { mass transfer and } \\
\text { chemical reaction }\end{array}$ & $\begin{array}{c}\cdot 673 \mathrm{~K} \\
\cdot \sim 200 \mathrm{mesh}\end{array}$ & Biomass, char, etc. were weighed. & $\begin{array}{l}\text { Using heat/mass transfer and } \\
\text { chemical reaction can well } \\
\text { represent the transient behavior. }\end{array}$ \\
\hline Klose and Wiest (1999) & Rotary kiln & 1D steady-state model & $\begin{array}{c}\cdot 450-800{ }^{\circ} \mathrm{C} \\
\cdot 10 \mathrm{~mm}\end{array}$ & $\begin{array}{l}\text { Condensed matters were determined } \\
\text { by proximate/ultimate analysis, and } \\
\text { gas analysis by was performed by } \\
\text { online GC. }\end{array}$ & $\begin{array}{l}\text { The influence of residence time } \\
\text { was small, and the model well } \\
\text { fitted with the experimental data. }\end{array}$ \\
\hline $\begin{array}{l}\text { Rath and Staudinger } \\
\text { (2001) }\end{array}$ & $\begin{array}{l}\text { Coupled TGA and the } \\
\text { tubular reactor }\end{array}$ & $\begin{array}{l}\text { Determined kinetic parameters } \\
\text { using a first-order kinetic } \\
\text { model and 1D flow model }\end{array}$ & $\begin{array}{c}\cdot 800{ }^{\circ} \mathrm{C} \\
\bullet 0.5-1.0 \mathrm{~mm}\end{array}$ & TGA curves were established. & $\begin{array}{l}\text { The model could predict } \mathrm{CO}, \mathrm{CO}_{2} \text {, } \\
\mathrm{H}_{2} \mathrm{O} \text {, hydrocarbons, acetylene, } \\
\text { methane, ethane, and propene. }\end{array}$ \\
\hline $\begin{array}{l}\text { Dupont et al. (2007); } \\
\text { Dupont et al. (2009) }\end{array}$ & $\begin{array}{l}\text { Lab-scale entrained flow } \\
\text { reactor }\end{array}$ & $\begin{array}{l}\text { Kinetic model, particle } \\
\text { decomposition model, and } \\
\text { reaction model. }\end{array}$ & $\begin{array}{l}\cdot 1073-1273 \mathrm{~K} \\
\cdot 0.4-1.1 \mathrm{~mm}\end{array}$ & $\begin{array}{l}\text { Solid in a decanter was collected. } \\
\text { Gas was analyzed by GC and FTIR. } \\
\text { Gas and solid masses at the reactor's } \\
\text { outlet were measured. }\end{array}$ & $\begin{array}{l}\text { It was concluded that the model } \\
\text { could be satisfactorily used for } \\
\text { prediction. }\end{array}$ \\
\hline Várhegyi et al. (2009) & TGA apparatus & $\begin{array}{l}\text { Distributed activation energy } \\
\text { model (DAEM) }\end{array}$ & $\begin{array}{c}\cdot 150-600{ }^{\circ} \mathrm{C} \\
\cdot 60 \mu \mathrm{m}\end{array}$ & $\begin{array}{l}\text { The least-squares evaluation for DTG } \\
\text { and TGA results were obtained. }\end{array}$ & $\begin{array}{l}\text { A good agreement with the } \\
\text { experimental data was achieved. }\end{array}$ \\
\hline Authier et al. (2009) & $\begin{array}{l}\text { Fluidized-bed reactor } \\
\quad \text { (image furnace) }\end{array}$ & $\begin{array}{c}\text { Eulerian and Lagrangian } \\
\text { approaches }\end{array}$ & $\begin{array}{c}\cdot 1800 \mathrm{~K} \\
\cdot \text { Various sizes }\end{array}$ & $\begin{array}{l}\text { Experiments were performed in an } \\
\text { image furnace. }\end{array}$ & $\begin{array}{l}\text { The gas and char yields and their } \\
\text { compositions depended on the } \\
\text { heating rate and temperature. }\end{array}$ \\
\hline Gerber et al. (2010) & Quartz glass reactor & Eulerian multiphase approach & $\begin{array}{c}\cdot 670 \mathrm{~K} \\
\cdot \text { Various sizes }\end{array}$ & $\begin{array}{l}\text { Thermocouples were used to monitor } \\
\text { the temperatures in the reactor. Gas } \\
\text { concentrations were examined at the } \\
\text { outlet of the reactor with GC and } \\
\text { laser MS. }\end{array}$ & $\begin{array}{l}\text { Operating conditions and model } \\
\text { parameters strongly influenced the } \\
\text { tar content in the gas. }\end{array}$ \\
\hline Hashimoto et al. (2011) & TGA apparatus & $\begin{array}{l}\text { A single nth-order reaction } \\
\text { model }\end{array}$ & $\begin{array}{l}\cdot 973-1273 \mathrm{~K} \\
\cdot 70-250 \mu \mathrm{m}\end{array}$ & $\begin{array}{l}\text { TGA curves were established and the } \\
\text { measurements of solid residue yield } \\
\text { were performed. }\end{array}$ & $\begin{array}{l}\text { A linear relationship existed } \\
\text { between residue yield and lignin } \\
\text { content of biomass. }\end{array}$ \\
\hline Xue et al. (2012) & $\begin{array}{l}\text { Bubbling fluidized-bed } \\
\text { reactor }\end{array}$ & $\begin{array}{l}\text { Euler multiphase CFD model } \\
\text { coupled }\end{array}$ & $\begin{array}{l}\cdot 700^{\circ} \mathrm{C} \\
.520 \mu \mathrm{m}\end{array}$ & $\begin{array}{l}\text { Model predictions are compared to } \\
\text { the experimental yields. }\end{array}$ & $\begin{array}{l}\text { Biomass size and gas velocity } \\
\text { influenced tar yield considerably. }\end{array}$ \\
\hline Bruchmüller et al. (2012) & Fluidized-bed reactor & $\begin{array}{c}\text { Eulerian-Lagrangian or CFD- } \\
\text { DEM model }\end{array}$ & $\begin{array}{l}\cdot 699-758 \mathrm{~K} \\
\cdot 0.5 \mathrm{~mm}\end{array}$ & $\begin{array}{l}\text { The steady-state experimental data } \\
\text { used to validate the fluidization } \\
\text { process. }\end{array}$ & $\begin{array}{l}\text { The fluidization velocity } \\
\text { remarkably affected the bio-oil } \\
\text { yield. }\end{array}$ \\
\hline Brown and Brown (2012) & Auger reactor & Regression models & $\begin{array}{l}\cdot 600{ }^{\circ} \mathrm{C} \\
\cdot 750 \mu \mathrm{m}\end{array}$ & $\begin{array}{l}\text { The bio-oil and char yields were } \\
\text { gravimetrically determined, and gas } \\
\text { yields were measured using Micro- } \\
\text { GC. }\end{array}$ & $\begin{array}{l}\text { Auger reactor was found suitable } \\
\text { for bio-oil production }\end{array}$ \\
\hline Xiong et al. (2014) & $\begin{array}{l}\text { Laboratory-scale } \\
\text { bubbling fluidized-bed } \\
\text { reactor }\end{array}$ & $\begin{array}{l}\text { Three kinetic schemes coupled } \\
\text { with multi-fluid models }\end{array}$ & $\begin{array}{c}\cdot 773 \mathrm{~K} \\
\cdot \text { Various sizes }\end{array}$ & $\begin{array}{l}\text { The predicted yields were compared } \\
\text { with experimental results. }\end{array}$ & $\begin{array}{l}\text { The three-component scheme was } \\
\text { the best one to represent biomass } \\
\text { pyrolysis. }\end{array}$ \\
\hline Xiong and Kong (2014) & Fluidized-bed reactor & $\begin{array}{l}\text { Multi-fluid model coupled } \\
\text { with chemical reactions }\end{array}$ & $\begin{array}{c}\cdot 773 \mathrm{~K} \\
\cdot 0.5 \mathrm{~mm}\end{array}$ & $\begin{array}{l}\text { All yields at the reactor exit were } \\
\text { presented. }\end{array}$ & $\begin{array}{l}\text { Increases in gas velocity and tar } \\
\text { convective flow could prevent the } \\
\text { tar from cracking into gas. }\end{array}$ \\
\hline Olaleye et al. (2014) & $\begin{array}{l}\text { Special designed 2-stage } \\
\text { fixed bed. }\end{array}$ & $\begin{array}{l}\text { A dynamic model considering } \\
\text { heat/mass transfer }\end{array}$ & $\cdot 800{ }^{\circ} \mathrm{C}$ & $\begin{array}{l}\text { Two condensers and dry ice were } \\
\text { employed to collect the final } \\
\text { products. The gases were collected in } \\
\text { a bag and analyzed by GC. }\end{array}$ & $\begin{array}{l}\text { The prediction was in a good } \\
\text { agreement with test data. }\end{array}$ \\
\hline Lee et al. (2015) & $\begin{array}{l}\text { Bubbling fluidized-bed } \\
\text { reactor with three-stage } \\
\text { condenser }\end{array}$ & $\begin{array}{l}\text { CFD models coupled with the } \\
\text { lumped model and hybrid } \\
\text { model }\end{array}$ & $\begin{array}{c}\bullet 873 \mathrm{~K} \\
\cdot \text { Various sizes }\end{array}$ & $\begin{array}{l}\text { The calculated yields were compared } \\
\text { with the tested results and with the } \\
\text { literature. }\end{array}$ & $\begin{array}{l}\text { Both lumped and hybrid models } \\
\text { could satisfactorily predict the char } \\
\text { yield. }\end{array}$ \\
\hline
\end{tabular}


Table 2.

continued.

\begin{tabular}{|c|c|c|c|c|c|}
\hline Authors & Reactor type & Model & $\begin{array}{l}\text { Temperature and } \\
\text { particle size }\end{array}$ & Validation remark(s) & Conclusions \\
\hline Dizaji et al. (2014) & TGA apparatus & First-order Arrhenius law & $\begin{array}{c}\bullet 1100 \mathrm{~K} \\
\cdot \text { Various sizes }\end{array}$ & $\begin{array}{l}\text { The weight loss curves versus } \\
\text { temperature were obtained. }\end{array}$ & $\begin{array}{l}\text { The mean pyrolysis rate was a } \\
\text { criterion to predict the volatility. }\end{array}$ \\
\hline Corbetta et al. (2014) & $\begin{array}{c}\text { Some unpopular reactors } \\
\text { for centimeter-scale } \\
\text { samples }\end{array}$ & $\begin{array}{l}\text { A kinetic model integrating the } \\
\text { chemical reactions and } \\
\text { heat } / \text { mass transfer }\end{array}$ & $\begin{array}{c}\cdot 468-1050{ }^{\circ} \mathrm{C} \\
\cdot 2-3 \mathrm{~cm}\end{array}$ & $\begin{array}{l}\text { Temperatures were measured using } \\
\text { K-type thermocouples. Mass loss as } \\
\text { well as gas and tar yields were } \\
\text { obtained using GC and FTIR. }\end{array}$ & $\begin{array}{l}\text { Prediction and experiment results } \\
\text { were reasonably fit. }\end{array}$ \\
\hline Wan et al. (2015) & A single-particle reactor & CPD for coal and straw & $\begin{array}{l}\cdot 1100 \mathrm{~K} \\
\cdot 0.8 \mathrm{~mm}\end{array}$ & $\begin{array}{l}\text { Mass loss was determined by TGA- } \\
\text { NMR. }\end{array}$ & $\begin{array}{l}\text { CPD model could simulate the } \\
\text { pyrolysis of coal and straw. }\end{array}$ \\
\hline Ranzi et al. (2017) & TGA apparatus & $\begin{array}{l}\text { The kinetic model used for } \\
\text { secondary reactions }\end{array}$ & $\begin{array}{c}\cdot 800{ }^{\circ} \mathrm{C} \\
\cdot \text { Various sizes }\end{array}$ & $\begin{array}{l}\text { TG data and reported data were } \\
\text { compared. }\end{array}$ & $\begin{array}{l}\text { Acceptable agreements with } \\
\text { experiments were observed. }\end{array}$ \\
\hline
\end{tabular}

$\mathrm{GC}$ = gas chromatography TGA = thermogravimetric analysis; $\mathrm{DTG}=$ derivative thermogravimetric analysis; $\mathrm{CPD}=$ chemical percolation devolatilization.

\section{vapor pressures.}

As another difficulty, the solid yields at the reactor outlet cannot be accurately measured because char particles leave the reactor in an erratic pattern and should be collected after extracting gas products, tar, and water (Bruchmüller et al., 2012). Bandyopadhyay et al. (1996) weighed solid samples of biomass and char at different time intervals, and the experiments had to be restarted and continued for the prescheduled time. The yields were determined using the method of weighted summative volatiles and char as well as the predetermined composition of the volatiles.

Dupont et al. (2009) weighed the solids in the decanter at the reactor's outlet, and the fine particles and remaining tars were separated on the gas filter. Hashimoto et al. (2011) used weights of solid residue yields of the pyrolysis and reported that the lignin content linearly affected the solid residue yield. Xue et al. (2012) weighed the chars and bio-oil collection system components at each time interval during pyrolysis, and the equation of mass balance was gravimetrically developed based on the masses of the bio-oil and chars. Brown and Brown (2012) applied response surface models for predicting the bio-oil and char yields by considering the interaction between the carrier gas flow and auger speed. Xiong and Kong (2014) presented all weight fractions of the pyrolysis yields at the reactor's exit. Lee et al. (2015) reported yields of biooil, syngas, and chars in their experiments and used the data to verify their models.

\subsubsection{Instrumentation-based approaches}

Due to the diversity of pyrolysis reactor conditions and biomass feedstocks, it is desirable to develop comprehensive models of biomass-pyrolysis, which can accurately predict yields of products based on the feedstock type, particle characteristics, and pyrolysis process conditions (Miller and Bellan, 1997; Miura and Maki, 1998). As a popular technique for examining the thermal characteristics during the biomass pyrolysis process, the TG-FTIR analysis can be used to generate kinetic input parameters and then produce quantitative results for different feedstocks, such as glucose, cellulose, hemicellulose, xylan, lignin, poplar and pine wood, wheat straw, bagasse, tobacco, and chlorogenic acid (Bassilakis et al., 2001; De Jong et al., 2003; De Jong et al., 2007). The kinetic parameters obtained by TG-FTIR analysis can be incorporated into a pyrolysis model to predict product yields (Wójtowicz et al., 2003). De Jong et al. (2003) used the TG-FTIR analysis to examine the characteristics of two materials and explore the role of different functional groups in devolatilization, vaporization, and cross-linking.

In a rotary kiln at temperatures ranging from $450-800{ }^{\circ} \mathrm{C}$, Klose and Wiest (1999) determined the concentrations of $\mathrm{CO}_{2}, \mathrm{CO}, \mathrm{CH}_{4}$, and $\mathrm{H}_{2}$ by an online packed-column GC/MS and the characteristics of condensed matters by proximate and ultimate analyses. This led to a balance between each product's mass and total mass and an energy balance using the gross calorific value as chemical enthalpy. Rath and Staudinger (2001) used TG curves to calculate the components of different gas products $\left(\mathrm{CO}, \mathrm{CO}_{2}, \mathrm{H}_{2} \mathrm{O}\right.$, hydrocarbons, acetylene, methane, ethane, and propene) produced in the pyrolysis process. Using the least-squares method, Várhegyi et al. (2009) analyzed the derivative thermogravimetric (DTG) and TGA data in separate calculations and simultaneously evaluated twelve pyrolysis experiments.

Dupont et al. (2009) placed some probes at different vertical positions in the reactor to examine the gas and solid products. The remaining particles and tars in the released gases were screened using a filter. The masses of syngas and solids were determined at the outlet of the reactor. Several methods were used to analyze gases, including the FTIR spectrometer for $\mathrm{CO}, \mathrm{CO}_{2}, \mathrm{CH}_{4}, \mathrm{C}_{2} \mathrm{H}_{4}, \mathrm{C}_{2} \mathrm{H}_{2}$, and $\mathrm{C}_{2} \mathrm{H}_{6}$, Non-Dispersive Infrared analyzer for $\mathrm{O}_{2}$ and $\mathrm{CO}_{2}$, Flame Ionization Detectors for $\mathrm{CH}_{4}$ and total hydrocarbons, Thermal Conductivity Detector for $\mathrm{H}_{2}$, and hygrometric mirror for $\mathrm{H}_{2} \mathrm{O}$. At least two measurement methods were performed for each gas component so that the errors between the two measurements were always smaller than $5 \%$. Although the temperature measurement inside the biomass particle was impossible and the inaccurate temperature distribution in the particles might have affected the heat transfer process, the examination of morphological changes of solid residue with different initial sizes confirmed the model with a reasonable accuracy. Using GC joined with laser MS, Gerber et al. (2010) examined gas concentrations at the outlet of the pyrolysis reactor.

Bruchmüller et al. (2012) used experimental results of the pyrolysis of 0.8 million wood particles in a fluidized-bed reactor to validate the Lagrangian CFD simulation results. They showed that the gas composition at the outlet determined by the unsteady-state method agreed well with that measured by the steady-state method. Olaleye et al. (2014) collected the final products by condensing them with two condensers and dry ice, and used the Tedlar ${ }^{\mathrm{TM}}$ bags to collect the gases and then analyzed off-line by GC. Dizaji et al. (2014) predicted the volatility of different materials by the mean pyrolysis rate based on the weight loss curves $v s$. temperature. Ranzi et al. (2017) used several TG-based experimental data and wide-ranged reported data in the previous literature to validate pyrolysis' kinetic parameters. Using coal and biomass as feedstock materials, Pielsticker et al. (2017) simultaneously measured the yields of 22 pyrolysis gases in a fluidized-bed reactor using FTIR by a novel sampling technique, i.e. offline measurements of gas species selection. This method required long FTIR scan times to capture enough gases for increasing the signal/noise ratio. Consecutively, the total pyrolysis yields were continuously measured online by the regular measurements of the simultaneous quantitative analysis.

\section{Applications of gas sensors and recommendations}

\subsection{Review of current gas sensors}

During the biomass pyrolysis, it is desirable to accurately estimate the syngas yield $\left(\mathrm{CO}_{2}, \mathrm{CO}, \mathrm{CH}_{4}\right.$, and $\left.\mathrm{H}_{2}\right)$. Different processes require different types of gas sensors due to their different physical and chemical properties. Many studies have focused on advancing the gas sensors in terms of miniaturization and high-temperature resistance (Lakkis et al., 2014). The current methods used for gas sensing are summarized as follows: 
a. Conducting polymer gas sensors are used for liquid petroleum gas sensing (Roy et al., 2011) and humidity measurement (Singh et al., 2012). In this type, the electrical resistance of the sensed gas is detected based on the gas interaction. As a major drawback, they are sensitive to the environmental parameters, such as high temperatures.

b. Piezoelectric surface acoustic wave (SAW) gas sensors were developed to measure the gas concentrations by determining acoustic wave speed varied by the different gas compositions (Toda and Kobayakawa, 2008; Fanget et al., 2011). The SAW sensor has two electrodes in gas, one is a transmitter, and the other is a receiver of acoustic waves. It has the advantages of low cost, precise, reproducible, and miniaturized size. As the primary idea, the surface wave is excited on a piezoelectric substrate (Jakubik, 2011). To detect the major gas species during the hightemperature biomass pyrolysis, Zhang et al. (2010, 2012 and 2016) and Zhang and Kosinski (2013) investigated the velocity shifts caused by high temperature in quartz SAW resonators by analyzing contributions of nonlinear material constants.

c. Carbon nanotubes-based gas sensors have been developed in two main types. The first one is based on single-walled nanotubes (SWNT) that include one layer of graphene. The second one is based on multi-walled nanotubes (MWNT) that involve about 50 layers of graphene. These sensors have the advantages of small size, low cost, and high sensitivity (Gavrilov et al., 2004; Kauffman and Star, 2008). When the sensors are exposed to gas molecules, the electrical resistance of the carbon nanotubes changes with the different molecules (Kong et al., 2000). The carbon nanotubes gas sensors also have the advantages of good selectivity and are not affected by surrounding situations (Modi et al., 2003).

d. Optical gas sensors include five types including optical spectroscopy sensor, non-dispersive infrared gas sensor, active laser gas sensor, surface Plasmon resonance (SPR) gas sensor, and optical fiber gas sensor (Lakkis et al., 2014). The optical spectroscopy gas sensor has the advantages of rapid detection and good sensitivity. However, this technique is expensive and can only measure the gas with a substantial optical absorption (Dakin and Chambers, 2006). The non-dispersive infrared gas sensor is used to measure the infrared (IR) light absorbed by the gas (Lee and Lee, 2001). The active laser gas sensor can remotely measure gas concentration, suitable for determining air contamination (Eremin, 2007). The SPR sensor has a thin metal film placed on a glass surface. It measures the intensity of the reflected signal from the varied angle of the light beam at a fixed wavelength (Jha and Sharma, 2011). The optical fiber gas sensor has a dye coating layer on the optical fiber surfaces, and the dye's optical properties vary with the interaction with different gases (Arshak et al., 2004). It has the advantages of small size and weight, remote operation, working in a highly noisy environment, and no power requirement (Elosua et al., 2006).

e. Semiconductor gas sensor is based on the interaction between metal oxides and the measured gas. As soon as the sensor absorbs the gases, oxidation occurs, resulting in a substantial change in electrical resistance (Yamazoe, 2005). The semiconductor sensor has the advantages of low cost, high sensitivity, and simplicity (Yamazoe, 2005). However, it suffers from less reproducibility, instability, and non-linearity.

f. Electrochemical gas sensor is popularly offered in the current market (Dubbe, 2003), mainly applied to detect oxygen level in the automotive industry (Gründler, 2007). The advantages are the shor response time, high precision, wide work range, and low power consumption. As the main drawback, it is not applicable for the processes taking place at the cryogenic temperature $\left(<-40{ }^{\circ} \mathrm{C}\right)$.

g. Ionization gas sensor is a type of gas sensors working based on the principle of physical reaction, in which the ionization characteristics of different gases act as their fingerprints (Pearce et al., 2006; Liao et al., 2008). In this sensor, each gas species can be ionized under a particular voltage, temperature, and pressure. Since different gas species have different ionization voltages, the ionization fingerprints

\section{To maximize the biomass pyrolysis efficiency and improve product quality}

\section{Biomass feedstock}
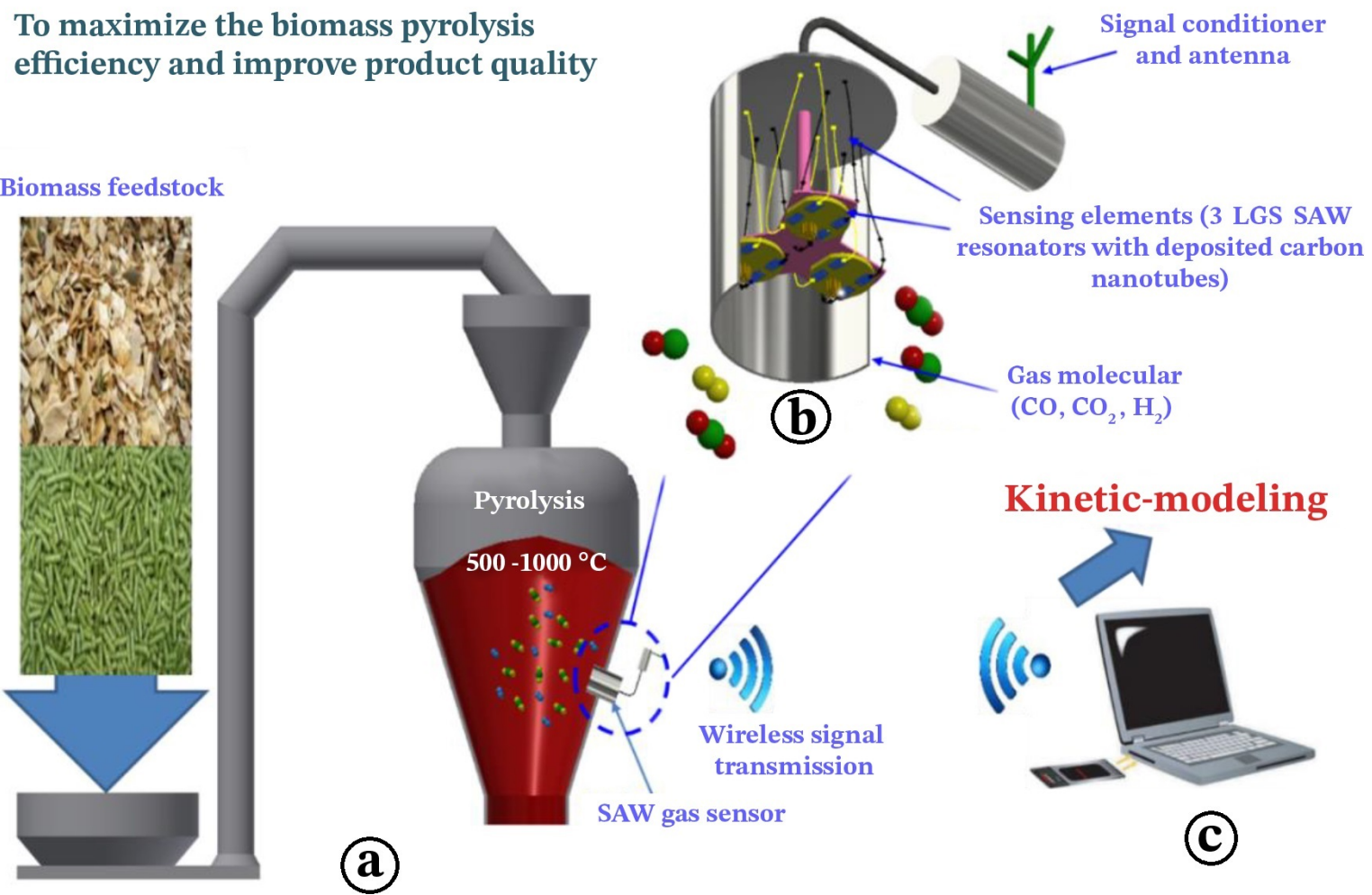

a

(C)

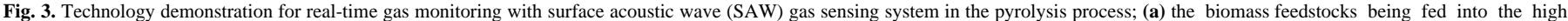
temperature gasifier; (b) the enlarged view of the langasite surface acoustic wave (LGS SAW) gas sensor and signal conditioner; and (c) PC with a wireless transmitter. 
of all gases can be identified. However, the ionization gas sensors have a large size and need high voltages and power consumption.

h. Silicon micromachined $\boldsymbol{G C}$ is the technique currently used for examining the gas fractions during pyrolysis. The principle of GC is that the sample gases are injected into the instrument with a carrier gas stream. The samples are then transferred into a separation tube where the various components of the gases are separated. A detector examines the quantity of the components exiting the tube. At this stage, the gas concentrations can be estimated by comparing the results with the standard gas samples with known concentrations (Zampolli et al., 2009). Although the GC system is precise, it has some limitations due to its large size, fragility, slowness, and high cost (Radadia et al., 2010). Furthermore, GC application provides insufficient volatility for species, limiting real-time gas separation and yield determination (Bourgonje et al., 2017).

Although the determination of the gas yields during the pyrolysis process using the Py-GC/MS system is a possible approach, its bulky size, fragility, slow detection, and high cost limit its industrial applications, particularly in real-time measurements. Thus, it is necessary to develop an innovative technique to accurately measure the gas yield in real-time. Recently, some research teams have focused on high-temperature gas sensors to achieve advanced gas sensing approaches for harsh environment applications (Ghosh et al., 2019a and b; Zhang et al., 2019). and power devices such as energy harvesters. In addition to this suggestion, it is also desirable to develop high-temperature sensors for online detection of the gaseous products during biomass pyrolysis. These sensors can facilitate the real-time monitoring of gases during the process, offering useful information for pyrolysis modeling, consequently leading to high product quality and process performance. Additional useful features for the gas sensors could be 1) wireless monitoring so that no high-temperatureresistant wire is needed and 2) simultaneous gas detection of $\mathrm{CO}, \mathrm{CO}_{2}$, and $\mathrm{H}_{2}$. The details of the suggested technology are presented in Figure 3 .

Figure 4 also suggests a gas sensor probe consisting of three-circular SAW resonators as the sensing element and the associated housing.

\section{Conclusions}

The present work reviewed the effects of feedstock characteristics, biomass shape and size, heat-mass transfer, particle motion, and reaction kinetics on the pyrolysis process and product yields. In addition, the experimental validation methods and current gas sensors for pyrolysis reactors were explained. The current techniques used for experimental validations including the determinations of temperatures, mass losses, and weight fractions were reviewed. Moreover, the applications of TGA, DTG, FTIR, and Py-GC/MS analyses for describing the pyrolysis process and estimating product yield were discussed.

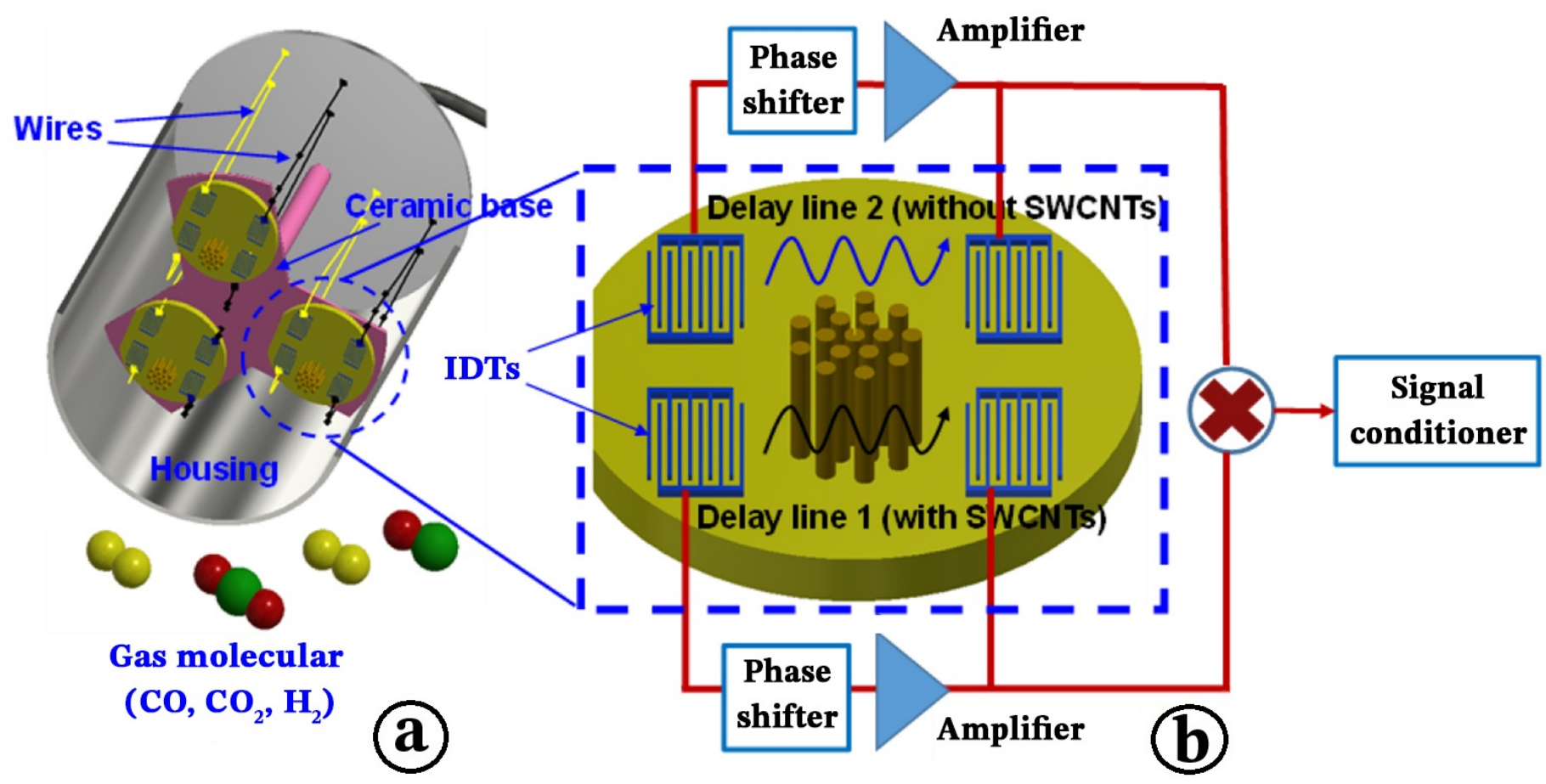

Fig. 4. The suggested gas sensor probe; (a) gas sensor probe and (b) enlarged view of the dual delay line langasite surface acoustic wave (LGS SAW) resonator.

\subsection{Recommendations for future works on gas sensors}

Future works are recommended to increase the SAW sensor's survival temperature from $350{ }^{\circ} \mathrm{C}$ to $600-1000^{\circ} \mathrm{C}$. That will include improving the hightemperature adhesive and sensor fixture and the high-temperature electronics
Most studies confirmed that the investigated models could accurately predict the product yields by superpositioning the associated values for individual biomass components. On the contrary, some researchers claimed that the interactions between the biomass components could hinder the 
accurate prediction for product yield. Nevertheless, the present paper demonstrated that well-established models could result in an acceptable accuracy. Moreover, the product validation technique was regarded as a crucial factor for evaluating models' effectiveness.

Among the various methods used for gas analysis, although the Py-GC/MS offers a suitable method for gas yield estimation, it suffers from the bulky size, fragility, slow detection, and high cost, limiting its industrial applications, particularly in real-time measurements. Therefore, it is highly recommended to develop an advanced technique to accurately measure the gas yield in real-time for the biomass pyrolysis.

\section{Acknowledgments}

This research is financially supported by the USDA NIFA Foundation Program Award (2017-67021-26138), and the Natural Science Foundation of Jiangsu Province (BK20200775). The authors are grateful to Dr. Eric Suuberg (Brown University) for his valuable suggestions throughout this work. The authors would also like to thank the Universiti Malaysia Terengganu under Golden Goose Research Grant Scheme (GGRG) (Vot 55191) for supporting Dr. Lam to perform this review project in collaboration with the Nanjing Forestry University.

\section{References}

[1] Abnisa, F., Daud, W.M.A.W., 2014. A review on co-pyrolysis of biomass: an optional technique to obtain a high-grade pyrolysis oil. Energy Convers. Manage. 87, 71-85.

[2] Aghbashlo, M., Almasi, F., Jafari, A., Nadian, M.H., Soltanian, S., Lam, S.S., Tabatabaei, M., 2021. Describing biomass pyrolysis kinetics using a generic hybrid intelligent model: a critical stage in sustainable wasteoriented biorefineries. Renewable Energy. 170, 81-91

[3] Aghbashlo, M., Tabatabaei, M., Nadian, M.H., Davoodnia, V., Soltanian, S., 2019. Prognostication of lignocellulosic biomass pyrolysis behavior using ANFIS model tuned by PSO algorithm. Fuel. 253, 189-198.

[4] Amen-Chen, C., Pakdel, H., Roy, C., 2001. Production of monomeric phenols by thermochemical conversion of biomass: a review. Bioresour. Technol. 79(3), 277-299

[5] Anca-Couce, A., Zobel, N., 2012. Numerical analysis of a biomass pyrolysis particle model: solution method optimized for the coupling to reactor models. Fuel. 97, 80-88.

[6] Antal, M.J., Mochidzuki, K., Paredes, L.S., 2003. Flash carbonization of biomass. Ind. Eng. Chem. Res. 42(16), 3690-3699.

[7] Apaydın-Varol, E., Pütün, A.E., 2012. Preparation and characterization of pyrolytic chars from different biomass samples. J. Anal. Appl. Pyrolysis. 98, 29-36.

[8] Arshak, K., Moore, E., Lyons, G.M., Harris, J., Clifford, S., 2004. A review of gas sensors employed in electronic nose applications. Sensor Rev. 24(2), 181-198.

[9] Asadieraghi, M., Daud, W.M.A.W., Abbas, H.F., 2015. Heterogeneous catalysts for advanced bio-fuel production through catalytic biomass pyrolysis vapor upgrading: a review. RSC Adv. 5(28), 22234-22255.

[10] Authier, O., Ferrer, M., Mauviel, G., Khalfi, A.E., Lédé, J., 2009. Wood fast pyrolysis: comparison of Lagrangian and Eulerian modeling approaches with experimental measurements. Ind. Eng. Chem. Res. 48(10), 4796-4809.

[11] Bandyopadhyay, S., Chowdhury, R., Biswas, G.K., 1996. Transient behavior of a coconut shell pyrolyzer: a mathematical analysis. Ind. Eng. Chem. Res. 35(10), 3347-3355.

[12] Baruah, D., Baruah, D.C., Hazarika, M.K., 2017. Artificial neural network based modeling of biomass gasification in fixed bed downdraft gasifiers. Biomass Bioenergy. 98, 264-271.

[13] Bassilakis, R., Carangelo, R.M., Wojtowicz, M.A., 2001. TG-FTIR analysis of biomass pyrolysis. Fuel. 80(12), 1765-1786.

[14] Bauer, W.D., Talmadge, K.W., Keegstra, K., Albersheim, P., 1973. The structure of plant cell walls II. the hemicellulose of the walls of suspension-cultured sycamore cells. Plant Physiol. 51(1), 174-187.

[15] Biagini, E., Barontini, F., Tognotti, L., 2006. Devolatilization of biomass fuels and biomass components studied by TG/FTIR technique. Ind. Eng. Chem. Res. 45(13), 4486-4493.
[16] Biagini, E., Fantei, A., Tognotti, L., 2008. Effect of the heating rate on the devolatilization of biomass residues. Thermochim. Acta 472(12), 55-63.

[17] Bitowft, B., Andersson, L.A., Bjerle, I., 1989. Fast pyrolysis of sawdust in an entrained flow reactor. Fuel. 68(5), 561-566.

[18] Bliek, A., Van Poelje, W.M., Van Swaaij, W.P.M., Van Beckum, F.P.H., 1985. Effects of intraparticle heat and mass transfer during devolatilization of a single coal particle. AIChE J. 31(10), 1666-1681.

[19] Bourgonje, Z.C., Veringa, H.J., Smeulders, D.M.J., 2017. The new method to characterize the gas emissions during torrefaction realtime. Fuel Process. Technol. 164, 24-32.

[20] Bradbury, A.G., Sakai, Y., Shafizadeh, F., 1979. A kinetic model for pyrolysis of cellulose. J. Appl. Polym. Sci. 23(11), 3271-3280.

[21] Bridgwater, A.V., Peacocke, G.V.C., 2000. Fast pyrolysis processes for biomass. Renew. Sust. Energy Rev. 4(1), 1-73.

[22] Bridgwater, A.V., 2003. Renewable fuels and chemicals by thermal processing of biomass. Chem. Eng. J. 91(2-3), 87-102.

[23] Bridgwater, A.V., 2012. Review of fast pyrolysis of biomass and product upgrading. Biomass Bioenergy. 38, 68-94.

[24] Brown, D.W., Fuchino, T., Maréchal, F.M., 2007. Stoichiometric equilibrium modelling of biomass gasification: Validation of artificia neural network temperature difference parameter regressions. J Chem. Eng. Japan. 40(3), 244-254.

[25] Brown, J.N., Brown, R.C., 2012. Process optimization of an auger pyrolyzer with heat carrier using response surface methodology. Bioresour. Technol. 103(1), 405-414.

[26] Bruchmüller, J., van Wachem, B.G.M., Gu, S., Luo, K.H., Brown, R.C., 2012. Modeling the thermochemical degradation of biomass inside a fast pyrolysis fluidized bed reactor. AICHE J. 58(10), 30303042

[27] Burhenne, L., Messmer, J., Aicher, T., Laborie, M.P., 2013. The effect of the biomass components lignin, cellulose and hemicellulose on TGA and fixed bed pyrolysis. J. Anal. Appl. Pyrolysis. 101, 177 184.

[28] Caballero, J.A., Font, R., Marcilla, A., 1996. Comparative study of the pyrolysis of almond shells and their fractions, holocellulose and lignin. product yields and kinetics. Thermochim. Acta. 276, 57-77.

[29] Cai, J., Wu, W., Liu, R., 2014. An overview of distributed activation energy model and its application in the pyrolysis of lignocellulosic biomass. Renew. Sust. Energy Rev. 36, 236-246.

[30] Cai, J., Wu, W., Liu, R., Huber, G.W., 2013. A distributed activation energy model for the pyrolysis of lignocellulosic biomass. Green Chem. 15(5), 1331-1340.

[31] Calvo-Flores, F.G., Dobado, J.A., 2010. Lignin as renewable raw material. ChemSusChem. 3(11), 1227-1235.

[32] Çepelioğullar, Ö., Mutlu, İ., Yaman, S., Haykiri-Acma, H., 2016. A study to predict pyrolytic behaviors of refuse-derived fuel (RDF) artificial neural network application. J. Anal. Appl. Pyrolysis 122, 84 94

[33] Chan, W.C.R., Kelbon, M., Krieger, B.B., 1985. Modelling and experimental verification of physical and chemical processes during pyrolysis of a large biomass particle. Fuel. 64(11), 1505-1513.

[34] Chi, M., Xu, X., Cui, D., Zhang, H., Wang, Q., 2016. A TG-FTIR investigation and kinetic analysis of oil shale kerogen pyrolysis using the distributed activation energy model. Oil Shale. 33(3), 228-247.

[35] Coats, A.W., Redfern, J.P., 1964. Kinetic parameters from thermogravimetric data. Nature. 201(4914), 68-69.

[36] Collard, F.X., Blin, J., 2014. A review on pyrolysis of biomass constituents: mechanisms and composition of the products obtained from the conversion of cellulose, hemicelluloses and lignin. Renew. Sust. Energy Rev. 38, 594-608.

[37] Corbetta, M., Frassoldati, A., Bennadji, H., Smith, K., Serapiglia, M.J., Gauthier, G., Melkior, T., Ranzi, E., Fisher, E.M., 2014. Pyrolysis of centimeter-scale woody biomass particles: kinetic modeling and experimental validation. Energy Fuels. 28(6), 3884 3898.

[38] Corella, J., Monzon, A., Santamaria, J., Gonzalez-Canibano, J., 1988 Ultra-fast biomass pyrolysis in a high-temperature (2200 C), fluidwall reactor. J. Sol. Energy Eng. 110(1), 10-13. 
[39] Couhert, C., Commandre, J.M., Salvador, S., 2009a. Is it possible to predict gas yields of any biomass after rapid pyrolysis at high temperature from its composition in cellulose, hemicellulose and lignin?. Fuel. 88(3), 408-417.

[40] Couhert, C., Commandré, J.M., Salvador, S., 2009b. Failure of the component additivity rule to predict gas yields of biomass in flash pyrolysis at $950^{\circ} \mathrm{C}$. Biomass Bioenergy. 33(2), 316-326.

[41] Dakin, J.P., Chambers, P., 2006. Review of methods of optical gas detection by direct optical spectroscopy, with emphasis on correlation spectroscopy. Optical Chemical Sensors. Springer, pp. 457-477.

[42] Das, P., Ganesh, A., Wangikar, P., 2004. Influence of pretreatment for deashing of sugarcane bagasse on pyrolysis products. Biomass Bioenergy. 27(5), 445-457.

[43] De Jong, W., Di Nola, G., Venneker, B.C.H., Spliethoff, H., Wójtowicz, M.A., 2007. TG-FTIR pyrolysis of coal and secondary biomass fuels: determination of pyrolysis kinetic parameters for main species and $\mathrm{NO}_{\mathrm{x}}$ precursors. Fuel. 86(15), 2367-2376.

[44] De Jong, W., Pirone, A., Wojtowicz, M.A., 2003. Pyrolysis of Miscanthus Giganteus and wood pellets: TG-FTIR analysis and reaction kinetics败. Fuel. 82(9), 1139-1147.

[45] de Souza, M.B., Couceiro, L., Barreto, A.G., Quitete, C.P.B., 2012. Neural network based modeling and operational optimization of biomass gasification processes. Gasification Pract. Appl. InTech. 297.

[46] Demirbaș, A., 2002. Gaseous products from biomass by pyrolysis and gasification: effects of catalyst on hydrogen yield. Energy Convers. Manage. 43(7), 897-909.

[47] Di Blasi, C., 1996. Heat, momentum and mass transport through a shrinking biomass particle exposed to thermal radiation. Chem. Eng. Sci. 51(7), 1121-1132.

[48] Di Blasi, C., 1998. Physico-chemical processes occurring inside a degrading two-dimensional anisotropic porous medium. Int. J. Heat Mass Transfer. 41(24), 4139-4150.

[49] Di Blasi, C., Branca, C., D’Errico, G., 2000. Degradation characteristics of straw and washed straw. Thermochim. Acta. 364(1-2), 133-142.

[50] Di Blasi, C., Lanzetta, M., 1997. Intrinsic kinetics of isothermal xylan degradation in inert atmosphere. J. Anal. Appl. Pyrolysis. 40-41, 287303.

[51] Di Blasi, C., Russo, G., 1993. Modeling of transport phenomena and kinetics of biomass pyrolysis. Advances in thermochemical biomass conversion. Springer, Dordrecht. pp. 906-921.

[52] Dizaji, H.B., Dizaji, F.F., Bidabadi, M., 2014. Determining thermokinetic constants in order to classify explosivity of foodstuffs. Combustion, Explosion, Shock Waves. 50(4), 454-462.

[53] Dong, C.Q., Zhang, Z.F., Lu, Q., Yang, Y.P., 2012. Characteristics and mechanism study of analytical fast pyrolysis of poplar wood. Energy Convers. Manage. 57, 49-59

[54] Doyle, C.D., 1965. Series approximations to the equation of thermogravimetric data. Nature. 207(4994), 290-291.

[55] Dubbe, A., 2003. Fundamentals of solid state ionic micro gas sensors. Sens. Actuators, B. 88(2), 138-148.

[56] Dupont, C., Boissonnet, G., Seiler, J.M., Gauthier, P., Schweich, D., 2007. Study about the kinetic processes of biomass steam gasification. Fuel. 86(1-2), 32-40.

[57] Dupont, C., Chen, L., Cances, J., Commandre, J.M., Cuoci, A., Pierucci, S., Ranzi, E., 2009. Biomass pyrolysis: kinetic modelling and experimental validation under high temperature and flash heating rate conditions. J. Anal. Appl. Pyrolysis. 85(1-2), 260-267.

[58] Elosua, C., Matias, I.R., Bariain, C., Arregui, F.J., 2006. Development of an in-fiber nanocavity towards detection of volatile organic gases. Sensors. 6(6), 578-592.

[59] Eremin, V.M.I., N.A.; Lyubchenko, F.N., 2007. Micromachined gas chromatography system.

[60] Fan, R., Fox, R.O., 2008. Segregation in polydisperse fluidized beds: validation of a multi-fluid model. Chem. Eng. Sci. 63(1), 272-285.

[61] Fan, R., Fox, R.O., Muhle, M.E., 2007. Role of intrinsic kinetics and catalyst particle size distribution in CFD simulations of polymerization reactors.

[62] Fan, R., Marchisio, D.L., Fox, R.O., 2004. Application of the direct quadrature method of moments to polydisperse gas-solid fluidized beds. Powder Technol. 139(1), 7-20.
[63] Fanget, S., Hentz, S., Puget, P., Arcamone, J., Matheron, M., Colinet E.D., Andreucci, P., Duraffourg, L., Myers, E., Roukes, M., 2011. Gas sensors based on gravimetric detection-a review. Sens. Actuators, B. 160(1), 804-821.

[64] Ferdous, D., Dalai, A.K., Bej, S.K., Thring, R.W., Bakhshi, N.N. 2001. Production of $\mathrm{H}_{2}$ and medium Btu gas via pyrolysis of lignins in a fixed-bed reactor. Fuel Process. Technol. 70(1), 9-26.

[65] Fletcher, D.F., Haynes, B.S., Christo, F.C., Joseph, S.D., 2000. A CFD based combustion model of an entrained flow biomass gasifier Appl. Math. Model. 24(3), 165-182.

[66] Fletcher, T.H., Kerstein, A.R., Pugmire, R.J., Solum, M.S., Grant, D.M., 1992. Chemical percolation model for devolatilization. 3 . direct use of carbon-13 NMR data to predict effects of coal type Energy Fuels. 6(4), 414-431.

[67] Fletcher, T.H., Pond, H.R., Webster, J., Wooters, J., Baxter, L.L., 2012. Prediction of tar and light gas during pyrolysis of black liquor and biomass. Energy Fuels. 26(6), 3381-3387.

[68] Flynn, J.H., 1997. The 'temperature integral'-its use and abuse. Thermochim. Acta 300(1-2), 83-92

[69] Friedman, H.L., 1964. Kinetics of thermal degradation of charforming plastics from thermogravimetry. application to a phenolic plastic. J. Polymer Sci. Polym. Symp. 6(1), 183-195.

[70] Garcia-Maraver, A., Salvachúa, D., Martínez, M.J., Diaz, L.F. Zamorano, M., 2013. Analysis of the relation between the cellulose hemicellulose and lignin content and the thermal behavior of residua biomass from olive trees. Waste Manage. 33(11), 2245-2249.

[71] Gavrilov, S.A., Il'ichev, E.A., Poltoratskii, E.A., Rychkov, G.S., Dvorkin, V.V., Dzbanovsky, N.N., Suetin, N.V., 2004. Carbon nanotube field emitters for planar emission vacuum micro-and nanoelectronics. Tech. Phys. Lett. 30(7), 609-611

[72] Ge, S., Foong, S.Y., Ma, N.L., Liew, R.K., Mahari, W.A.W., Xia, C., Yek, P.N.Y., Peng, W., Nam, W.L., Lim, X.Y., Liew, C.M., Chong, C.C., Sonne, C., Lam, S.S., 2020a. Vacuum pyrolysis incorporating microwave heating and base mixture modification: an integrated approach to transform biowaste into eco-friendly bioenergy products. Renew. Sust. Energy Rev. 127, 109871

[73] Ge, S., Wu, Y., Peng, W., Xia, C., Mei, C., Cai, L., Shi, S.Q., Sonne, C., Lam, S.S., Tsang, Y.F., 2020b. High-pressure $\mathrm{CO}_{2}$ hydrotherma pretreatment of peanut shells for enzymatic hydrolysis conversion into glucose. Chem. Eng. J. 385, 123949.

[74] Geng, J., Wang, W.L., Yu, Y.X., Chang, J.M., Cai, L.p., Shi, S.Q. 2017. Adding nickel formate in alkali lignin to increase contents of alkylphenols and aromatics during fast pyrolysis. Bioresour. Technol. 227, 1-6

[75] Gerber, S., Behrendt, F., Oevermann, M., 2010. An Eulerian modeling approach of wood gasification in a bubbling fluidized bed reactor using char as bed material. Fuel. 89(10), 2903-2917.

[76] Ghosh, A., Zhang, C., Shi, S.Q., Zhang, H., 2019a. High-temperature gas sensors for harsh environment applications: a review. Clean (Weinh), 47(8), 1800491.

[77] Ghosh, A., Zhang, C., Shi, S., Zhang, H., 2019b. High temperature $\mathrm{CO} 2$ sensing and its cross-sensitivity towards $\mathrm{H}_{2}$ and $\mathrm{CO}$ gas using calcium doped $\mathrm{ZnO}$ thin film coated langasite SAW sensor. Sens. Actuators B Chem. 301, 126958.

[78] Goodwin, T.W., Mercer, E., 1972. Introduction to plant biochemistry.

[79] Gründler, P., 2007. Chemical sensors: an introduction for scientists and engineers. Springer Science \& Business Media.

[80] Guo, B., Li, D., Cheng, C., Lü, Z.a., Shen, Y., 2001. Simulation of biomass gasification with a hybrid neural network model. Bioresour. Technol. 76(2), 77-83

[81] Haider, A., Levenspiel, O., 1989. Drag coefficient and terminal velocity of spherical and nonspherical particles. Powder Technol. 58(1), 63-70.

[82] Hashimoto, K., Hasegawa, I., Hayashi, J., Mae, K., 2011 Correlations of kinetic parameters in biomass pyrolysis with solic residue yield and lignin content. Fuel. 90(1), 104-112.

[83] Horbaj, P., 1997. Model of the kinetics of biomass pyrolysis. Drevársky výskum 42(4), 15-23

[84] Hu, J., Xiao, R., Shen, D., Zhang, H., 2013. Structural analysis of lignin residue from black liquor and its thermal performance in 
thermogravimetric-Fourier transform infrared spectroscopy. Bioresour. Technol. 128, 633-639.

[85] Hu, M., Chen, Z., Wang, S., Guo, D., Ma, C., Zhou, Y., Chen, J., Laghari, M., Fazal, S., Xiao, B., 2016. Thermogravimetric kinetics of lignocellulosic biomass slow pyrolysis using distributed activation energy model, Fraser-Suzuki deconvolution, and iso-conversional method. Energy Convers. Manage. 118, 1-11.

[86] Huang, Q.X., Wang, R.P., Li, W.J., Tang, Y.J., Chi, Y., Yan, J.H., 2014. Modeling and experimental studies of the effects of volume shrinkage on the pyrolysis of waste wood sphere. Energy Fuels. 28(10), 6398-6406.

[87] Isahak, W.N.R.W., Hisham, M.W., Yarmo, M.A., Hin, T.y.Y., 2012. A review on bio-oil production from biomass by using pyrolysis method. Renew. Sust. Energy Rev. 16(8), 5910-5923.

[88] Jakab, E., Faix, O., Till, F., Székely, T., 1995. Thermogravimetry/mass spectrometry study of six lignins within the scope of an international round robin test. J. Anal. Appl. Pyrolysis. 35(2), 167-179.

[89] Jakubik, W.P., 2011. Surface acoustic wave-based gas sensors. Thin Solid Films. 520(3), 986-993.

[90] Jalan, R.K., Srivastava, V.K., 1999. Studies on pyrolysis of a single biomass cylindrical pellet-kinetic and heat transfer effects. Energy Convers. Manage. 40(5), 467-494.

[91] Janse, A.M.C., Westerhout, R.W.J., Prins, W., 2000. Modelling of flash pyrolysis of a single wood particle. Chem. Eng. Process. 39(3), 239-252.

[92] Jha, R., Sharma, A.K., 2011. Design considerations for plasmonicexcitation based optical detection of liquid and gas media in infrared. Sens. Actuators, A. 165(2), 271-275.

[93] Jiang, G., Nowakowski, D.J., Bridgwater, A.V., 2010. Effect of the temperature on the composition of lignin pyrolysis products. Energy Fuels. 24(8), 4470-4475.

[94] Kan, T., Strezov, V., Evans, T.J., 2016. Lignocellulosic biomass pyrolysis: a review of product properties and effects of pyrolysis parameters. Renew. Sust. Energy Rev. 57, 1126-1140.

[95] Kauffman, D.R., Star, A., 2008. Carbon nanotube gas and vapor sensors. Angew. Chem. Int. Ed. 47(35), 6550-6570.

[96] Klose, W., Wiest, W., 1999. Experiments and mathematical modeling of maize pyrolysis in a rotary kiln. Fuel. 78(1), 65-72.

[97] Kong, J., Franklin, N.R., Zhou, C., Chapline, M.G., Peng, S., Cho, K., Dai, H., 2000. Nanotube molecular wires as chemical sensors. Science. 287(5453), 622-625.

[98] Kong, S.H., Lam, S.S., Yek, P.N.Y., Liew, R.K., Ma, N.L., Osman, M.S., Wong, C.C., 2019. Self-purging microwave pyrolysis: an innovative approach to convert oil palm shell into carbon-rich biochar for methylene blue adsorption. J. Chem. Technol. Biotechnol. 94(5), 1397-1405.

[99] Kumar, S.S., Sathyabalan, P., Ragunathan, S., 2016. Simulation of Biomass Downdraft Gasifier based on Neural Networks. Asian J. Res. Social Sci. Humanities. 6(6), 1548-1560.

[100]Lakkis, S., Younes, R., Alayli, Y., Sawan, M., 2014. Review of recent trends in gas sensing technologies and their miniaturization potential. Sens. Rev. 34(1), 24-35.

[101]Lam, S.S., Azwar, E., Peng, W., Tsang, Y.F., Ma, N.L., Liu, Z., Park, Y.K., Kwon, E.E., 2019a. Cleaner conversion of bamboo into carbon fibre with favourable physicochemical and capacitive properties via microwave pyrolysis combining with solvent extraction and chemical impregnation. J. Clean. Prod. 236, 117692.

[102]Lam, S.S., Lee, X.Y., Nam, W.L., Phang, X.Y., Liew, R.K., Yek, P.N., Ho, Y.L., Ma, N.L., Rosli, M.H., 2019b. Microwave vacuum pyrolysis conversion of waste mushroom substrate into biochar for use as growth medium in mushroom cultivation. J. Chem. Technol. Biotechnol. 94(5), $1406-1415$

[103]Lam, S.S., Su, M.H., Nam, W.L., Thoo, D.S., Ng, C.M., Liew, R.K., Yek, P.N., Ma, N.L., Dai Viet Nguyen, V., 2019c. Microwave pyrolysis with steam activation in producing activated carbon for removal of herbicides in agricultural surface water. Ind. Eng. Chem. Res. 58(2), 695-703.

[104]Lam, S.S., Mahari, W.A.W., Ma, N.L., Azwar, E., Kwon, E.E., Peng, W., Chong, C.T., Liu, Z., Park, Y.K., 2019d. Microwave pyrolysis valorization of used baby diaper. Chemosphere. 230, 294-302

[105] Lam, S.S., Mahari, W.A.W., Ok, Y.S., Peng, W., Chong, C.T., Ma, N.L., Chase, H.A., Liew, Z., Yusup, S., Kwon, E.E., Tsang, D.C.W., 2019e. Microwave vacuum pyrolysis of waste plastic and used cooking oil for simultaneous waste reduction and sustainable energy conversion: recovery of cleaner liquid fuel and techno-economic analysis. Renew. Sust. Energy Rev. 115, 109359

[106] Lathouwers, D., Bellan, J., 2001. Yield optimization and scaling of fluidized beds for tar production from biomass. Energy Fuels. 15(5), $1247-1262$

[107] Lee, D.D., Lee, D.S., 2001. Environmental gas sensors. IEEE Sens. J. 1(3), 214-224

[108] Lee, Y.R., Choi, H.S., Park, H.C., Lee, J.E., 2015. A numerical study on biomass fast pyrolysis process: a comparison between full lumped modeling and hybrid modeling combined with CFD. Comput. Chem. Eng. 82, 202-215.

[109] Leonard, J., Kramer, M.A., 1990. Improvement of the backpropagation algorithm for training neural networks. Comput. Chem. Eng. 14(3), 337-341.

[110] Lewis, A.D., Fletcher, T.H., 2013. Prediction of sawdust pyrolysis yields from a flat-flame burner using the CPD model. Energy Fuels. 27(2), 942-953.

[111] Li, S., Xu, S., Liu, S., Yang, C., Lu, Q., 2004. Fast pyrolysis of biomass in free-fall reactor for hydrogen-rich gas. Fuel Process. Technol. 85(8-10), 1201-1211

[112] Li, Y., Liu, Y., Chen, W., Wang, Q., Liu, Y., Li, J., Yu, H., 2016 Facile extraction of cellulose nanocrystals from wood using ethano and peroxide solvothermal pretreatment followed by ultrasonic nanofibrillation. Green Chem. 18(4), 1010-1018.

[113] Liao, L., Lu, H.B., Shuai, M., Li, J.C., Liu, Y.L., Liu, C., Shen, Z.X. Yu, T., 2008. A novel gas sensor based on field ionization from $\mathrm{ZnO}$ nanowires: moderate working voltage and high stability. Nanotechnology. 19(17), 175501.

[114] Liew, R.K., Chong, M.Y., Osazuwa, O.U., Nam, W.L., Phang, X.Y., Su, M.H., Cheng, C.K., Chong, C.T., Lam, S.S., 2018. Production of activated carbon as catalyst support by microwave pyrolysis of palm kernel shell: a comparative study of chemical versus physical activation. Res. Chem. Intermed. 44(6), 3849-3865

[115] Liliedahl, T., Sjöström, K., 1998. Heat transfer controlled pyrolysis kinetics of a biomass slab, rod or sphere. Biomass Bioenergy. 15(6), 503-509.

[116] Lin, T., Goos, E., Riedel, U., 2013. A sectional approach for biomass: modelling the pyrolysis of cellulose. Fuel Process. Technol. 115, 246 253.

[117] Lin, Y.C., Huber, G.W., 2009. The critical role of heterogeneous catalysis in lignocellulosic biomass conversion. Energy Environ. Sci. 2(1), 68-80.

[118] Liu, B., Papadikis, K., Gu, S., Fidalgo, B., Longhurst, P., Li, Z. Kolios, A., 2017. CFD modelling of particle shrinkage in a fluidized bed for biomass fast pyrolysis with quadrature method of moment. Fuel Process. Technol. 164, 51-68.

[119] Liu, Q., Wang, S., Zheng, Y., Luo, Z., Cen, K., 2008. Mechanism study of wood lignin pyrolysis by using TG-FTIR analysis. J. Anal. Appl. Pyrolysis. 82(1), 170-177.

[120] Lu, P., Hsieh, Y.L., 2010. Preparation and properties of cellulose nanocrystals: rods, spheres, and network. Carbohydr. Polym. 82(2), 329-336

[121] Lu, Q., Li, W.Z., Zhu, X.F., 2009. Overview of fuel properties of biomass fast pyrolysis oils. Energy Convers. Manage. 50(5), 1376 1383.

[122] Lu, Q., Yang, X.C., Dong, C.Q., Zhang, Z.F., Zhang, X.M., Zhu, X.F., 2011. Influence of pyrolysis temperature and time on the cellulose fast pyrolysis products: Analytical Py-GC/MS study. J. Anal. Appl. Pyrolysis. 92(2), 430-438.

[123] Luik, H., Luik, L., Tiikma, L., Vink, N., 2007. Parallels between slow pyrolysis of Estonian oil shale and forest biomass residues. J. Anal Appl. Pyrolysis. 79(1-2), 205-209.

[124] Ma, Z., Custodis, V., van Bokhoven, J.A., 2014. Selective deoxygenation of lignin during catalytic fast pyrolysis. Catal. Sci. Technol. 4(3), 766-772.

[125] Macquarrie, D.J., Clark, J.H., Fitzpatrick, E., 2012. The microwave pyrolysis of biomass. Biofuels Bioprod. Biorefin. 6(5), 549-560.

[126]Mahari, W.A.W., Chong, C.T., Cheng, C.K., Lee, C.L., Hendrata, K., Yek, P.N.Y., Ma, N.L., Lam, S.S., 2018a. Production of value-added 
liquid fuel via microwave co-pyrolysis of used frying oil and plastic waste. Energy. 162, 309-317.

[127]Mahari, W.A.W., Chong, C.T., Lam, W.H., Anuar, T.N.S.T., Ma, N.L., Ibrahim, M.D., Lam, S.S., 2018b. Microwave co-pyrolysis of waste polyolefins and waste cooking oil: influence of $\mathrm{N}_{2}$ atmosphere versus vacuum environment. Energy Convers. Manage. 171, 1292-1301.

[128] Mani, T., Murugan, P., Mahinpey, N., 2008. Determination of distributed activation energy model kinetic parameters using simulated annealing optimization method for nonisothermal pyrolysis of lignin. Ind. Eng. Chem. Res. 48(3), 1464-1467.

[129] Marchisio, D.L., Fox, R.O., 2005. Solution of population balance equations using the direct quadrature method of moments. J. Aerosol Sci. $36(1), 43-73$

[130] McKendry, P., 2002. Energy production from biomass (part 1): overview of biomass. Bioresour. Technol. 83(1), 37-46.

[131] Mellin, P., Kantarelis, E., Yang, W., 2014. Computational fluid dynamics modeling of biomass fast pyrolysis in a fluidized bed reactor, using a comprehensive chemistry scheme. Fuel. 117, 704-715.

[132] Mellin, P., Zhang, Q., Kantarelis, E., Yang, W., 2013. An Euler-Euler approach to modeling biomass fast pyrolysis in fluidized-bed reactorsFocusing on the gas phase. Appl. Therm. Eng. 58(1-2), 344-353.

[133] Meng, A., Zhou, H., Qin, L., Zhang, Y., Li, Q., 2013. Quantitative and kinetic TG-FTIR investigation on three kinds of biomass pyrolysis. J. Anal. Appl. Pyrolysis. 104, 28-37.

[134] Mikulandrić, R., Lončar, D., Böhning, D., Böhme, R., Beckmann, M., 2014. Artificial neural network modelling approach for a biomass gasification process in fixed bed gasifiers. Energy Convers. Manage. 87, 1210-1223

[135] Miller, R.S., Bellan, J., 1996. Analysis of reaction products and conversion time in the pyrolysis of cellulose and wood particles. Combust. Sci. Technol. 119(1-6), 331-373.

[136] Miller, R.S., Bellan, J., 1997. A generalized biomass pyrolysis model based on superimposed cellulose, hemicelluloseand liqnin kinetics. Combust. Sci. Technol. 126(1-6), 97-137.

[137] Milosavljevic, I., Oja, V., Suuberg, E.M., 1996. Thermal effects in cellulose pyrolysis: relationship to char formation processes. Ind. Eng. Chem. Res. 35(3), 653-662.

[138] Miura, K., Maki, T., 1998. A simple method for estimating $f(E)$ and $k 0$ $(E)$ in the distributed activation energy model. Energy Fuels. 12(5), 864869

[139] Modi, A., Koratkar, N., Lass, E., Wei, B., Ajayan, P.M., 2003. Miniaturized gas ionization sensors using carbon nanotubes. Nature. 424(6945), 171-174.

[140] Mohan, D., Pittman Jr, C.U., Steele, P.H., 2006. Pyrolysis of wood/biomass for bio-oil: a critical review. Energy Fuels. 20(3), 848889.

[141] Morgan Jr, H.M., Bu, Q., Liang, J., Liu, Y., Mao, H., Shi, A., Lei, H., Ruan, R., 2017. A review of catalytic microwave pyrolysis of lignocellulosic biomass for value-added fuel and chemicals. Bioresour. Technol. 230, 112-121

[142]Morsi, S.A.J., Alexander, A.J., 1972. An investigation of particle trajectories in two-phase flow systems. J. Fluid Mech. 55(2), 193-208.

[143]Oja, V., Suuberg, E.M., 1999. Vapor pressures and enthalpies of sublimation of $\mathrm{D}^{- \text {glucose, }} \mathrm{D}$-Xylose, cellobiose, and levoglucosan. J. Chem. Eng. Data. 44(1), 26-29.

[144] Olaleye, A.K., Adedayo, K.J., Wu, C., Nahil, M.A., Wang, M., Williams, P.T., 2014. Experimental study, dynamic modelling, validation and analysis of hydrogen production from biomass pyrolysis/gasification of biomass in a two-stage fixed bed reaction system. Fuel. 137, 364-374.

[145]Paine III, J.B., Pithawalla, Y.B., Naworal, J.D., 2008. Carbohydrate pyrolysis mechanisms from isotopic labeling Part 4. The pyrolysis Of Dglucose: the formation of furans. J. Anal. Appl. Pyrolysis. 83(1), 37-63.

[146] Papadikis, K., Bridgwater, A.V., Gu, S., 2008. CFD modelling of the fast pyrolysis of biomass in fluidised bed reactors, Part A: eulerian computation of momentum transport in bubbling fluidised beds. Chem. Eng. Sci. 63(16), 4218-4227.

[147] Papadikis, K., Gu, S., Bridgwater, A.V., 2009. CFD modelling of the fast pyrolysis of biomass in fluidised bed reactors: modelling the impact of biomass shrinkage. Chem. Eng. J. 149(1-3), 417-427.
[148]Papadikis, K., Gu, S., Bridgwater, A.V., 2010. Computational modelling of the impact of particle size to the heat transfer coefficient between biomass particles and a fluidised bed. Fuel Process. Technol. 91(1), 68-79

[149]Papari, S., Hawboldt, K., 2015. A review on the pyrolysis of woody biomass to bio-oil: focus on kinetic models. Renew. Sust. Energy Rev. 52, 1580-1595.

[150]Passalacqua, A., Fox, R.O., Garg, R., Subramaniam, S., 2010. A fully coupled quadrature-based moment method for dilute to moderately dilute fluid-particle flows. Chem. Eng. Sci. 65(7), 2267-2283.

[151]Patwardhan, P.R., Brown, R.C., Shanks, B.H., 2011. Product distribution from the fast pyrolysis of hemicellulose. ChemSusChem. 4(5), 636-643.

[152]Patwardhan, P.R., Satrio, J.A., Brown, R.C., Shanks, B.H., 2009 Product distribution from fast pyrolysis of glucose-based carbohydrates. J. Anal. Appl. Pyrolysis. 86(2), 323-330.

[153]Pearce, T.C., Schiffman, S.S., Nagle, H.T., Gardner, J.W., 2006. Handbook of machine olfaction: electronic nose technology. John Wiley \& Sons.

[154]Pepiot, P., Dibble, C.J., Foust, T.D., 2010. Computational fluid dynamics modeling of biomass gasification and pyrolysis Computational Modeling in Lignocellulosic Biofuel Production. American Chemical Society, pp. 273-298.

[155]Peters, B., 2011. Prediction of pyrolysis of pistachio shells based on its components hemicellulose, cellulose and lignin. Fuel Process. Technol. 92(10), 1993-1998.

[156]Peters, B., Bruch, C., 2003. Drying and pyrolysis of wood particles experiments and simulation. J. Anal. Appl. Pyrolysis. 70(2), 233-250.

[157]Phanphanich, M., Mani, S., 2011. Impact of torrefaction on the grindability and fuel characteristics of forest biomass. Bioresour. Technol. 102(2), 1246-1253.

[158]Pielsticker, S., Gövert, B., Kreitzberg, T., Habermehl, M., Hatzfeld, O., Kneer, R., 2017. Simultaneous investigation into the yields of 22 pyrolysis gases from coal and biomass in a small-scale fluidized bed reactor. Fuel. 190, 420-434

[159]Pierucci, S., Ranzi, E., 2008. A general mathematical model for a moving bed gasifier. Comput. Aided Chem. Eng. 25, 901-906.

[160]Piskorz, J., Majerski, P., Radlein, D., Vladars-Usas, A., Scott, D.S. 2000. Flash pyrolysis of cellulose for production of anhydrooligomers. J. Anal. Appl. Pyrolysis. 56(2), 145-166

[161]Ponder, G.R., Richards, G.N., 1991. Thermal synthesis and pyrolysis of a xylan. Carbohydr. Res. 218, 143-155

[162]Pouwels, A.D., Eijkel, G.B., Boon, J.J., 1989. Curie-point pyrolysiscapillary gas chromatography-high-resolution mass spectrometry of microcrystalline cellulose. J. Anal. Appl. Pyrolysis 14(4), 237-280.

[163]Puig-Arnavat, M., Hernández, J.A., Bruno, J.C., Coronas, A., 2013. Artificial neural network models for biomass gasification in fluidized bed gasifiers. Biomass Bioenergy. 49, 279-289.

[164]Radadia, A., Salehi-Khojin, A., Masel, R., Shannon, M., 2010. The effect of microcolumn geometry on the performance of micro-gas chromatography columns for chip scale gas analyzers. Sens. Actuators, B. 150(1), 456-464.

[165]Radlein, D., Quignard, A., 2013. A short historical review of fast pyrolysis of biomass. Oil Gas Sci. Technol. Rev. d'IFP Energies nouvelles. 68(4), 765-783.

[166]Ranzi, E., Cuoci, A., Faravelli, T., Frassoldati, A., Migliavacca, G., Pierucci, S., Sommariva, S., 2008. Chemical kinetics of biomass pyrolysis. Energy Fuels. 22(6), 4292-4300.

[167]Ranzi, E., Debiagi, P.E.A., Frassoldati, A., 2017. Mathematical modeling of fast biomass pyrolysis and bio-oil formation. Note I: kinetic mechanism of biomass pyrolysis. ACS Sustain. Chem. Eng. 5(4), 2867-2881

[168]Rao, T.R., Sharma, A., 1998. Pyrolysis rates of biomass materials Energy. 23(11), 973-978.

[169]Rath, J., Staudinger, G., 2001. Cracking reactions of tar from pyrolysis of spruce wood. Fuel. 80(10), 1379-1389.

[170]Ren, S., Lei, H., Wang, L., Bu, Q., Chen, S., Wu, J., 2013. Therma behaviour and kinetic study for woody biomass torrefaction and torrefied biomass pyrolysis by TGA. Biosyst. Eng. 116(4), 420-426. 
[171]Rostami, A.A., Hajaligol, M.R., Wrenn, S.E., 2004. A biomass pyrolysis sub-model for CFD applications. Fuel. 83(11-12), 1519-1525.

[172]Roy, A.S., Machappa, T., Prasad, M.A., Anilkumar, K.R., 2011. Sensitivity and selectivity studies on polyaniline/molybdenum trioxide composites to liquid petroleum gas. Sens. Transducers. 125(2), 220.

[173] Saastamoinen, J.J., 2006. Simplified model for calculation of devolatilization in fluidized beds. Fuel. 85(17-18), 2388-2395.

[174]Sanders, E.B., Goldsmith, A.I., Seeman, J.I., 2003. A model that distinguishes the pyrolysis of D-glucose, D-fructose, and sucrose from that of cellulose. application to the understanding of cigarette smoke formation. J. Anal. Appl. Pyrolysis. 66(1-2), 29-50.

[175]Scheller, H.V., Ulvskov, P., 2010. Hemicelluloses. Annu. Rev. Plant Biol. 61.

[176]Scott, D.S., Majerski, P., Piskorz, J., Radlein, D., 1999. A second look at fast pyrolysis of biomass-the RTI process. J. Anal. Appl. Pyrolysis. 51(12), 23-37.

[177] Shafizadeh, F., 1982. Introduction to pyrolysis of biomass. J. Anal. Appl. Pyrolysis 3(4), 283-305.

[178] Shafizadeh, F., Fu, Y., 1973. Pyrolysis of cellulose. Carbohydr. Res. 29(1), 113-122.

[179] Sharma, A., Pareek, V., Zhang, D., 2015. Biomass pyrolysis-a review of modelling, process parameters and catalytic studies. Renew. Sust. Energy Rev. 50, 1081-1096.

[180] Shen, D., Gu, S., 2009. The mechanism for thermal decomposition of cellulose and its main products. Bioresour. Technol. 100(24), 6496-6504.

[181]Shen, D.K., Gu, S., Bridgwater, A.V., 2010a. The thermal performance of the polysaccharides extracted from hardwood: cellulose and hemicellulose. Carbohydr. Polym. 82(1), 39-45.

[182] Shen, D.K., Gu, S., Luo, K.H., Wang, S.R., Fang, M.X., 2010b. The pyrolytic degradation of wood-derived lignin from pulping process. Bioresour. Technol. 101(15), 6136-6146.

[183] Shen, D., Xiao, R., Gu, S., Luo, K., 2011. The pyrolytic behavior of cellulose in lignocellulosic biomass: a review. RSC Adv. 1(9), 16411660

[184]Shen, Y., Yoshikawa, K., 2013. Recent progresses in catalytic tar elimination during biomass gasification or pyrolysis-a review. Renew. Sust. Energy Rev. 21, 371-392.

[185]Sheng, C., Azevedo, J.L.T., 2002. Modeling biomass devolatilization using the chemical percolation devolatilization model for the main components. Proc. Combust. Inst.. 29(1), 407-414

[186]Shi, S.Q., Xia, C., 2017. Porositization process of carbon or carbonaceous materials. Google Patents.

[187]Shoja, M., Babatabar, M.A., Tavasoli, A., Ataei, A., 2013. Production of hydrogen and syngas via pyrolysis of bagasse in a dual bed reactor. J. Energy Chem. 22(4), 639-644.

[188]Si, H.P., Wu, Z.D., Wu, J.H., Chen, J., Lin, K.Y., 2015. Review on pyrolysis carbonization technology of biomass. Adv. Mater. Res. 1092, 72-78.

[189]Singh, S., Verma, N., Yadav, B.C., Prakash, R., 2012. A comparative study on surface morphological investigations of ferric oxide for LPG and opto-electronic humidity sensors. Appl. Surf. Sci. 258(22), 8780-8789.

[190] Sonobe, T., Worasuwannarak, N., 2008. Kinetic analyses of biomass pyrolysis using the distributed activation energy model. Fuel. 87(3), 414421

[191]Soltanian, S., Aghbashlo, M., Almasi, F., Hosseinzadeh-Bandbafha, H., Nizami, A.S., Ok, Y.S., Lam, S.S., Tabatabaei, M., 2020. A critical review of the effects of pretreatment methods on the exergetic aspects of lignocellulosic biofuels. Energy Convers. Manage. 212, 112792.

[192] Spearpoint, M.J., 1999. Predicting the ignition and burning rate of wood in the cone calorimeter using an integral model. research directed by Dept. of Fire Protection Engineering.University of Maryland, College Park.

[193] Starink, M.J., 2003. The determination of activation energy from linear heating rate experiments: a comparison of the accuracy of isoconversion methods. Thermochim. Acta. 404(1-2), 163-176.

[194]Sun, Y., Liu, L., Wang, Q., Yang, X., Tu, X., 2016. Pyrolysis products from industrial waste biomass based on a neural network model. J. Anal. Appl. Pyrolysis. 120, 94-102.

[195]Sunphorka, S., Chalermsinsuwan, B., Piumsomboon, P., 2015. Application of artificial neural network for kinetic parameters prediction of biomass oxidation from biomass properties. J. Energy Inst. 90(1) $51-61$.

[196] Sunphorka, S., Chalermsinsuwan, B., Piumsomboon, P., 2017. Artificial neural network model for the prediction of kinetic parameters of biomass pyrolysis from its constituents. Fuel. 193, 142 158 .

[197] Suuberg, E.M., Milosavljevic, I., Oja, V., 1996. Two-regime global kinetics of cellulose pyrolysis: the role of tar evaporation. Symp. (International) on Combust. 26(1), 1515-1521.

[198]Suuberg, E.M., Peters, W.A., Howard, J.B., 1978. Product composition and kinetics of lignite pyrolysis. Ind. Eng. Chem. Process Des. Dev. 17(1), 37-46.

[199]Thunman, H., Leckner, B., Niklasson, F., Johnsson, F., 2002. Combustion of wood particles-a particle model for eulerian calculations. Combust. Flame. 129(1-2), 30-46.

[200]Toda, H., Kobayakawa, T., 2008. High-speed gas concentration measurement using ultrasound. Sens. Actuators, A. 144(1), 1-6.

[201]Tran, D.Q., Rai, C., 1978. A kinetic model for pyrolysis of Douglas fir bark. Fuel. 57(5), 293-298.

[202]Trendewicz, A., Braun, R., Dutta, A., Ziegler, J., 2014. One dimensional steady-state circulating fluidized-bed reactor model for biomass fast pyrolysis. Fuel. 133, 253-262.

[203]Tripathi, M., Sahu, J.N., Ganesan, P., 2016. Effect of process parameters on production of biochar from biomass waste through pyrolysis: a review. Renew. Sust. Energy Rev. 55, 467-481.

[204]Uzun, B.B., Pütün, A.E., Pütün, E., 2007. Composition of products obtained via fast pyrolysis of olive-oil residue: effect of pyrolysis temperature. J. Anal. Appl. Pyrolysis. 79(1-2), 147-153.

[205] Van de Velden, M., Baeyens, J., Brems, A., Janssens, B., Dewil, R., 2010. Fundamentals, kinetics and endothermicity of the biomass pyrolysis reaction. Renewable Energy. 35(1), 232-242.

[206] van der Hoef, M.A., van Sint Annaland, M., Deen, N.G., Kuipers, J.A.M., 2008. Numerical simulation of dense gas-solid fluidized beds: a multiscale modeling strategy. Annu. Rev. Fluid Mech. 40, 47 70 .

[207] Várhegyi, G., Chen, H., Godoy, S., 2009. Thermal decomposition of wheat, oat, barley, and Brassica carinata straws. a kinetic study. Energy Fuels. 23(2), 646-652

[208]Vizzini, G., Bardi, A., Biagini, E., Falcitelli, M., Tognotti, L., 2008. Prediction of rapid biomass devolatilization yields with an upgraded version of the bio-CPD model. Combustion Institute Italian section.

[209]Vyazovkin, S., Wight, C.A., 1999. Model-free and model-fitting approaches to kinetic analysis of isothermal and nonisothermal data. Thermochim. Acta. 340-341, 53-68.

[210]Wan, K., Wang, Z., He, Y., Xia, J., Zhou, Z., Zhou, J., Cen, K., 2015. Experimental and modeling study of pyrolysis of coal, biomass and blended coal-biomass particles. Fuel. 139, 356-364.

[211]Wang, Q., Wang, H., Sun, B., Bai, J., Guan, X., 2009. Interactions between oil shale and its semi-coke during co-combustion. Fuel 88(8), 1520-1529.

[212]Wang, Q., Zhao, Y., Zhang, Y., 2014. Shrinkage kinetics of largesized briquettes during pyrolysis and its application in tamped coal cakes from large-scale chambers. Fuel. 138, 1-14

[213]Wang, S., Guo, X., Liang, T., Zhou, Y., Luo, Z., 2012. Mechanism research on cellulose pyrolysis by Py-GC/MS and subsequent density functional theory studies. Bioresour. Technol. 104, 722-728.

[214]Wang, S., Wang, K., Liu, Q., Gu, Y., Luo, Z., Cen, K., Fransson, T., 2009. Comparison of the pyrolysis behavior of lignins from different tree species. Biotechnol. Adv. 27(5), 562-567.

[215]Wang, W.L., Chang, J.M., Cai, L.P., Shi, S.Q., 2014. Quality improvement of pyrolysis oil from waste rubber by adding sawdust. Waste Manage. 34(12), 2603-2610.

[216]Wang, W.L., Ren, X.Y., Chang, J.M., Cai, L.P., Shi, S.Q., 2015 Characterization of bio-oils and bio-chars obtained from the catalytic pyrolysis of alkali lignin with metal chlorides. Fuel Process. Technol. 138, 605-611.

[217]Werner, K., Pommer, L., Broström, M., 2014. Thermal decomposition of hemicelluloses. J. Anal. Appl. Pyrolysis 110, 130137. 
[218]White, J.E., Catallo, W.J., Legendre, B.L., 2011. Biomass pyrolysis kinetics: a comparative critical review with relevant agricultural residue case studies. J. Anal. Appl. Pyrolysis. 91(1), 1-33.

[219]Witek-Krowiak, A., Chojnacka, K., Podstawczyk, D., Dawiec, A., Pokomeda, K., 2014. Application of response surface methodology and artificial neural network methods in modelling and optimization of biosorption process. Bioresour. Technol. 160, 150-160.

[220]Wójtowicz, M.A., Bassilakis, R., Smith, W.W., Chen, Y., Carangelo, R.M., 2003. Modeling the evolution of volatile species during tobacco pyrolysis. J. Anal. Appl. Pyrolysis. 66(1-2), 235-261.

[221]Wooten, J.B., Seeman, J.I., Hajaligol, M.R., 2004. Observation and characterization of cellulose pyrolysis intermediates by ${ }^{13} \mathrm{C}$ CPMAS NMR. a new mechanistic model. Energy Fuels. 18(1), 1-15.

[222]Xia, C., Kang, C., Patel, M.D., Cai, L., Gwalani, B., Banerjee, R., Shi, S.Q., Choi, W., 2016. Pine Wood extracted activated carbon through selfactivation process for high-performance lithium-ion battery. ChemistrySelect. 1(13), 4000-4007.

[223]Xia, C., Shi, S.Q., 2016. Self-activation for activated carbon from biomass: theory and parameters. Green Chem. 18(7), 2063-2071.

[224]Xiong, Q., Aramideh, S., Kong, S.C., 2014. Assessment of devolatilization schemes in predicting product yields of biomass fast pyrolysis. Environ. Prog. Sustain. Energy. 33(3), 756-761.

[225]Xiong, Q., Kong, S.C., 2014. Modeling effects of interphase transport coefficients on biomass pyrolysis in fluidized beds. Powder Technol. 262, 96-105

[226]Xiong, Q., Zhang, J., Xu, F., Wiggins, G., Daw, C.S., 2016. Coupling DAEM and CFD for simulating biomass fast pyrolysis in fluidized beds. J. Anal. Appl. Pyrolysis. 117, 176-181

[227]Xue, Q., Dalluge, D., Heindel, T.J., Fox, R.O., Brown, R.C., 2012. Experimental validation and CFD modeling study of biomass fast pyrolysis in fluidized-bed reactors. Fuel. 97, 757-769.

[228]Xue, Q., Fox, R.O., 2014. Computational modeling of biomass thermochemical conversion in fluidized beds: particle density variation and size distribution. Ind. Eng. Chem. Res. 54(16), 4084-4094.

[229]Xue, Q., Heindel, T.J, Fox, R.O., 2011. A CFD model for biomass fast pyrolysis in fluidized-bed reactors. Chem. Eng. Sci. 66(11), 2440-2452.

[230]Yaman, S., 2004. Pyrolysis of biomass to produce fuels and chemical feedstocks. Energy Convers. Manage. 45(5), 651-671.

[231] Yamazoe, N., 2005. Toward innovations of gas sensor technology. Sens. Actuators, B. 108(1-2), 2-14

[232] Yang, H., Yan, R., Chen, H., Lee, D.H., Zheng, C., 2007. Characteristics of hemicellulose, cellulose and lignin pyrolysis. Fuel. 86(12-13), 17811788

[233] Yang, H., Yan, R., Chen, H., Zheng, C., Lee, D.H., Liang, D.T., 2006a. In-depth investigation of biomass pyrolysis based on three major components: hemicellulose, cellulose and lignin. Energy Fuels. 20(1), 388-393.

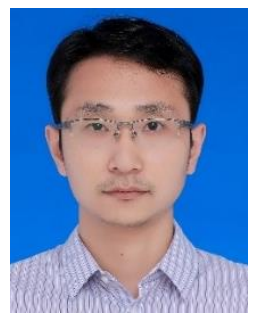

Dr. Changlei Xia is a Professor (2019-now) in the Department of Wood Science and Engineering at Nanjing Forestry University (China), and has been servicing as Dean Assistant (2020-now) at College of Materials Science and Engineering. He received BSc. and MSc. degrees in Polymer Science and Engineering in 2007 and 2010, respectively, at University of Science and Technology of China, and $\mathrm{PhD}$ degree (2016) in Mechanical and Energy Engineering at University of North Texas (USA). He was a Postdoctoral Fellow at University of Cincinnati and University of North Texas (USA). Dr. Xia has served as a member of Elsevier Advisory Panel, Associate Editor (Journal of Sustainable Science and Management), Topic Editor (Nutrients, Frontiers in Energy Research), and Guest Editor (Environmental Pollution, Advances in Polymer Technology). His research interests are centered on the development and utilization of biomass-based materials and energy.
[234]Yang, H., Yan, R., Chen, H., Zheng, C., Lee, D.H., Liang, D.T. 2006b. Influence of mineral matter on pyrolysis of palm oil wastes. Combust. Flame. 146(4), 605-611.

[235]Yek, P.N.Y., Liew, R.K., Osma, M.S., Lee, C.L., Chuah, J.H., Park, Y.K., Lam, S.S., 2019. Microwave steam activation, an innovative pyrolysis approach to convert waste palm shell into highly microporous activated carbon. J. Environ. Manage. 236, 245-253.

[236]Yin, C., 2012. Microwave-assisted pyrolysis of biomass for liquid biofuels production. Bioresour. Technol. 120, 273-284.

[237]Zampolli, S., Elmi, I., Mancarella, F., Betti, P., Dalcanale, E., Cardinali, G.C., Severi, M., 2009. Real-time monitoring of sub-ppb concentrations of aromatic volatiles with a MEMS-enabled miniaturized gas-chromatograph. Sens. Actuators, B. 141(1), 322328.

[238]Zanzi, R., Sjöström, K., Björnbom, E., 1996. Rapid high-temperature pyrolysis of biomass in a free-fall reactor. Fuel. 75(5), 545-550

[239]Zanzi, R., Sjöström, K., Björnbom, E., 2002. Rapid pyrolysis of agricultural residues at high temperature. Biomass Bioenergy. 23(5), 357-366

[240]Zhang, G., Wen, Y., Liu, Z., Zhang, S., Li, G., 2017. Acid-catalyzed hydrolysis of conifer lignosulfonate in black liquor for the production of value-added chemicals. Appl. Catal., A. 542, 1-9.

[241]Zhang, H., Kosinski, J.A., 2013. Analysis of contributions of nonlinear material constants to stress-induced velocity shifts of quartz and langasite surface acoustic wave resonators. IEEE Explore. 60(5), 975-985

[242]Zhang, H., Kosinski, J.A., Zuo, L., 2016. Analysis of contributions of nonlinear material constants to temperature-induced velocity shifts of quartz surface acoustic wave resonators. Ultrasonics. 71, 189-193.

[243]Zhang, H., Montz, B.D., Fan, T., Kosinski, J.A., 2012. Wireless langasite resonator as a force sensor. In 2012 IEEE International Frequency Control Symposium (FCS). IEEE. 1-6.

[244]Zhang, H., Turner, J.A., Yang, J., Kosinski, J.A., 2010. Forcefrequency effect of thickness mode langasite resonators. Ultrasonics. 50(4-5), 479-490.

[245]Zhang, Q., Chang, J., Wang, T., Xu, Y., 2007. Review of biomass pyrolysis oil properties and upgrading research. Energy Convers. Manage. 48(1), 87-92

[246]Zhang, C., Ghosh, A., Zhang, H., 2019. Langasite-based BAW resonator coated with $\mathrm{ZnO}$ for high temperature $\mathrm{CO}_{2}$ gas sensing with temperature compensation (Conference Presentation). In Sensors and Smart Structures Technologies for Civil, Mechanical, and Aerospace Systems 2019 (Vol. 10970, p. 109702B). International Society for Optics and Photonics.

[247]Zhao, J., Xiuwen, W., Hu, J., Liu, Q., Shen, D., Xiao, R., 2014 Thermal degradation of softwood lignin and hardwood lignin by TGFTIR and Py-GC/MS. Polym. Degrad. Stab. 108, 133-138.

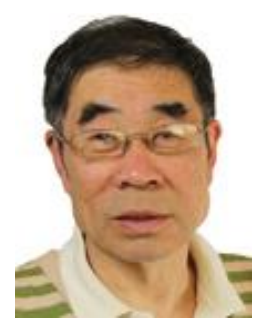

Dr. Liping Cai is a Research Professor in Mechanical Engineering Department at the University of North Texas (UNT), USA. He served as a research scientist at FPInnovations in Canada for 13 years before joining UNT in December 2012. He has over 30 years of experience in mechanical engineering, biomass production and building materials related research. Dr. Cai conducted research in areas such as simulation of heat and mass transfer in various materials, development of biomaterials for buildings and modelling the manufacturing of composites, vacuum-assisted resin infusion technology, tornado hazard for structure engineering, etc. He published over 200 papers in over 40 journals. 


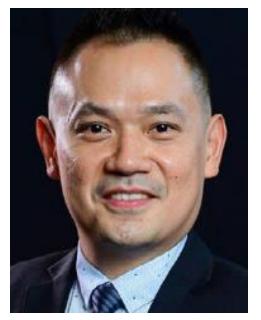

Su Shiung Lam is a Professor at Universiti Malaysia Terengganu (UMT) and a Core Member of Institute of Tropical Aquaculture and Fisheries (AKUATROP), accredited as the Higher Institution Centre of Excellence (HICoE) for Future Food: Sustainable Shellfish Aquaculture by Ministry of Higher Education Malaysia. He is selected as 2020 Top Research Scientists Malaysia and Member of Young Scientists Network by Academy of Sciences Malaysia. His academic background covers mainly Environmental Engineering, with a focus on Waste and Biomass Utilization, Waste and Wastewater Treatment, and Green Technology. He has professional qualification as Certified Environmental Professional for Hazardous Waste Management in Malaysia, and Professional Technologist for Green Technology by the Malaysia Board of Technologists. He has published over 200 papers, including one in Lancet (IF: 60.4), one in Nature (IF: 42.8), four in Science (IF: 41.8), one in Progress in Energy and Combustion Science (IF: 28.9), seven in Renewable and Sustainable Energy Reviews (IF: 12.1); eight currently ranked as Web of Science ESI "Highly Cited Papers" (Top 1\%) and one as ESI Hot paper (Top 0.1\%), receiving an h-index of $\mathbf{4 0}$ and $>\mathbf{4 0 0 0}$ citations on Google Scholar. Internationally, Lam is appointed as Chair Professor of Henan Province (China), Distinguished Professor of Nanjing Forestry University (China), Visiting Professor of Henan Agricultural University (China), and his affiliation as Central Council/Core Member of International Bioprocessing Association. Lam also contributes his service as Deputy Editor-in- Chief of Journal of Sustainability Science and Management (Scopus-indexed), Associate Editor for Environmental Advances (Elsevier), Environmental Geochemistry and Health (Springer, IF: 3.5), Frontiers in Energy Research (Frontiers, IF: 2.7) and Energy \& Environment (SAGE, IF: 1.8), Editorial Board Member for Bioresource Technology (Elsevier, IF: 7.5), Renewable and Sustainable Energy Transition (Elsevier), and Materials Science for Energy Technologies (Elsevier), and as Guest Editor of special issues in Journal of Hazardous Materials (Elsevier, IF: 9.0), Bioresource Technology (Elsevier, IF: 7.5), Environmental Pollution (Elsevier, IF: 6.8, Q1), Environ- mental Research (Elsevier, IF: 5.7), and Journal of Analytical and Applied Pyrolysis (Elsevier, IF: 3.9).

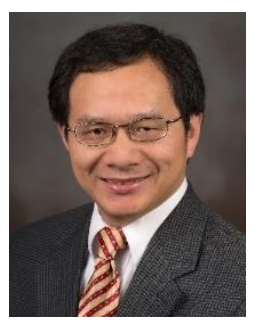

Lei Zuo is the Robert E. Hord Jr. Professor at Virginia Tech (USA) and Chief Research Scientist in the Energy and Environment Directorate at PNNL. He also directs the NSF Industry-University Cooperative Research Center for Energy Harvesting Materials and Systems. His research interests include energy harvesting, marine energy, vibration control, mechatronics design, self-powered sensors, and advanced manufacturing. He has authored over 300 papers and advised over $60 \mathrm{PhD}$ and Master students to completion of their degrees. Prof. Zuo has received several prestigious awards for his research, including two R\&D 100 Awards (2015 and 2011) by R\&D Magazine, the 2017 ASME Leonardo Da Vinci Award, the 2015 ASME Thar Energy Design Award,and 2014 SAE Ralph R. Teetor Educational Award. He completed his Ph.D. from MIT and is a Fellow of ASME.

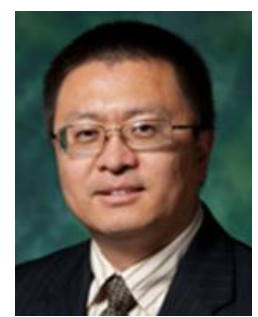

Dr. Sheldon Shi is a Professor at Mechanical Engineering Department, University of North Texas (UNT), USA. He is the registered Professional Engineer (PE) in Texas. He is the Fellow of Society of Wood Science and Technology (SWST). He has been elected as Director Board Member, Vice President, President Elect, and President for the SWST. Dr. Shi obtained his Ph.D. degree at Michigan Technological University (MTU) in 1997. After about two-year research experience as a Post-Doctorate Research Associate at both MTU and University of Maine, he joined APA - The Engineered Wood Association in 1999 as a Engineer conducting product evaluation and quality assurance of engineered wood based products for building construction. In 2004, he joined the faculty at Mississippi State University (MSU) as an Assistant Professor and received tenure. After seven years of service with MSU, Dr. Shi joined the UNT. Dr. Shi has been experienced in the manufacture processes of composite materials using biomass as feedstock, such as wood, plant fibers, soybean, etc. His expertise is on the processing and evaluation of bio-based composites, adhesive and adhesion, bond durability of the composite materials, and biomass to carbon conversion. Dr. Shi has published over 200 peer-reviewed papers and over 100 proceedings and presentations.

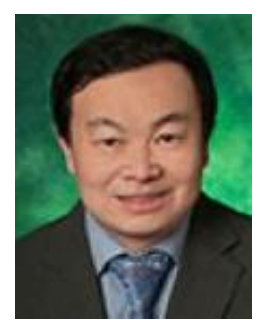

Dr. Haifeng Zhang is a Professor of the Department of Mechanical Engineering at the University of North Texas (Denton, TX, USA). His research interests include innovative sensing and energy harvesting devices in harsh environments, MEMS gas sensors, novel piezoelectric material characterization, structural health monitoring and nondestructive test methods. He received his B.S. in Engineering Mechanics from Hunan University, China in 1997, his M.S. degree in Solid Mechanics from Northwestern Polytechnical University, Xian, China, in 2001, and his $\mathrm{Ph} . \mathrm{D}$. degree in Engineering Mechanics from University of Nebraska, Lincoln in 2007. He was a postdoctoral researcher in the Department of Material Science and Engineering in the Ohio State University before joining in University of North Texas in 2008. He is the elected member of ASME Adaptive structure and materials branch and member of the ASME Energy Harvesting Technical Committee (EHTC). 